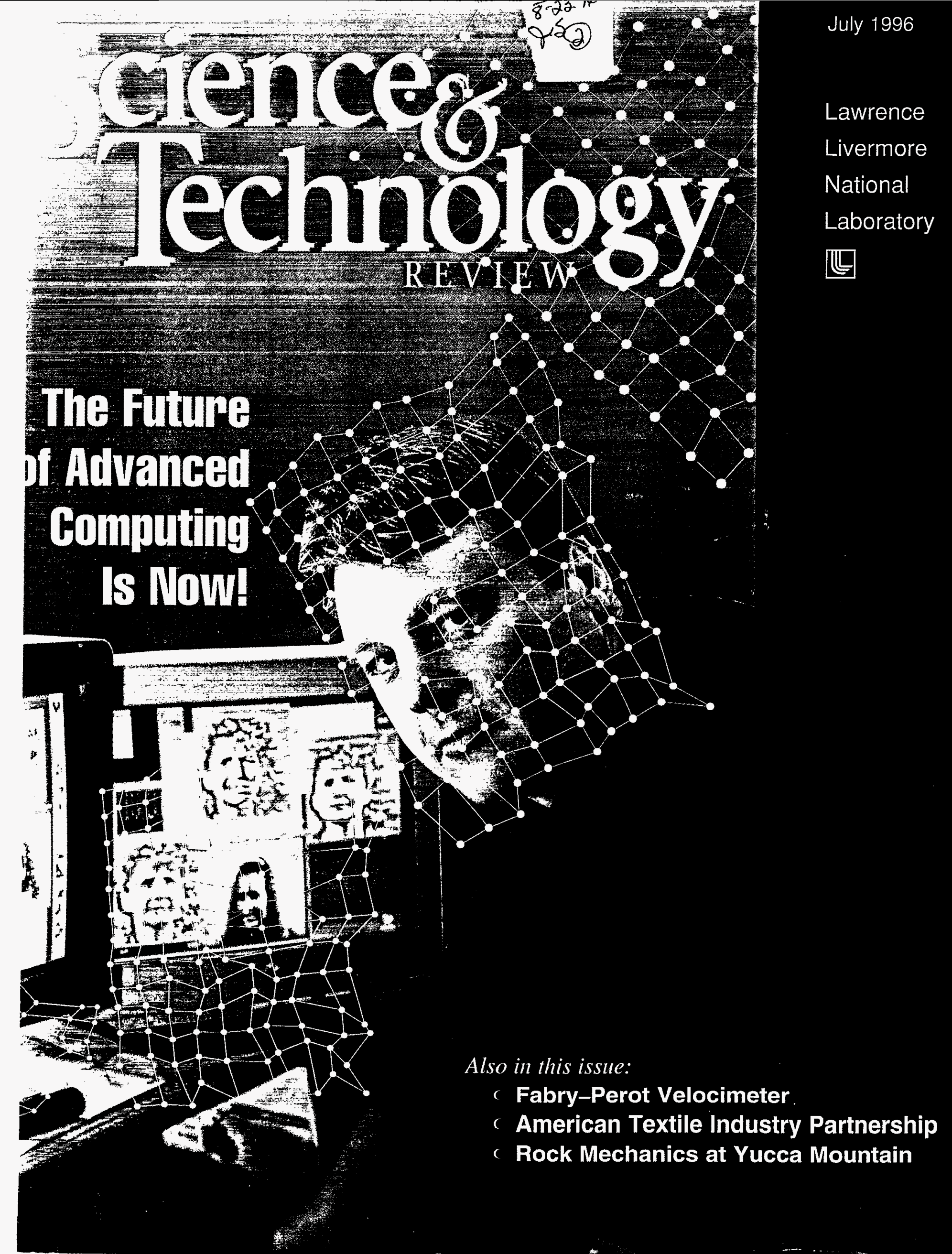


Martin Lades, a member of the Laboratory"s Institute for Scicntific Computing Research (ISCR) works with KEN, a near-real-time facerecognition computer technology developed at L.LNL. KEN is one of many applications being developed by the ISCR, which was recently reorganized to foster collaborative research in ikdvanced computing techniques. The Institute is exploring innovative and inventive advanced computer applications in partnership with programs and clients both inside and outside the I.ahoratory in areas such as computational physics. massively parallel processing. computer vision. and biomechanical modeling. Turn to p. 4 for our report on how the ISCR is exploring the ironters of advanced computational research.

We want to know what you think of our publication. Please use the enclosed survey form to give us your feedback.

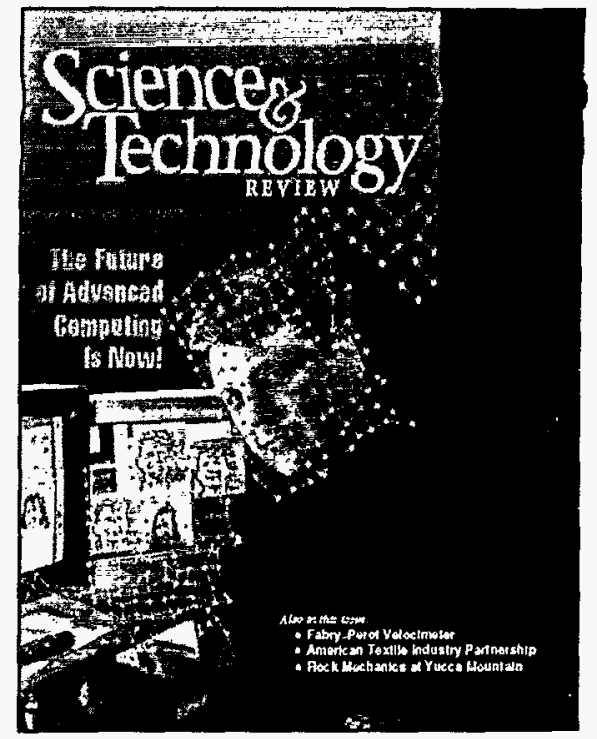

S\&TR is available on the Internet at http://nw\%:/hl.gor/str/str.html. As references become available on the Internet. they will be interactively linked to the footnote references at the end of each article. If you desire more detailed information about an article. click on any reference that is in color at the end of the article. and you will connect automatically with the reference.

The Lawrence Livermore National Laboratory. operated by the University of California for the United States Department of Energy, was established in 1952 to do research on nuclear weapons and magnetic fusion energy. Science \& Technology Review (formerly Energy) \& Technology Revi('). is published ten times a year to communicate, to a broad audience, the Laboratory's scientific and technological accomplishments, particularly in the Laboratory's core mission areas-global security. energy and the environment. and bioscience and biotechnology. The publication's goal is to help readers understand these accomplishments and appreciate their value to the individual citizen, the nation. and the world.

Please address any correspondence (including name and address changes) to S\&TR. Mail Stop L-66t.

Prepared by $\mathbf{L L}$ NL under contract No. W-7405-Eng-48 (510) 422-8961. Our electronic mail address is hunter6@llnl.gov. 


\section{S\&TR Staff}

SCIENTIFIC Editor

Becky Failor

Publication Editor

Dean Wheatcraft

\section{WrITERS}

Robert D. Kirvel, Ann Parker,

Dale Sprouse, and Katie Walter

\section{ARt Director}

Kathryn Tinsley

Designer

Kathryn Tinsley

Graphic ARTist

Treva Carey

Compositor

Louisa Cardoza

Proofreader

Catherine $\mathrm{M}$. Williams

S\&TR is produced by the Technical Information Department as a service for the Director's Office.

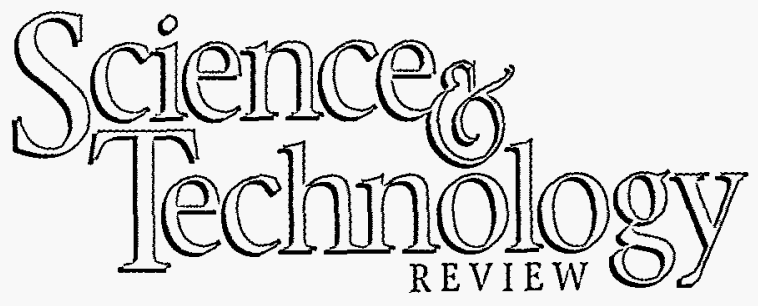

July 1996

Lawrence

Livermore

National

Laboratory
2 The Laboratory in the News

3 Commentary on the University Relations Program

\section{Features}

4 Frontiers of Research in Advanced Computations

The Laboratory's Institute for Scientific Computing Research has been reorganized to foster collaborative research in advanced computing techniques. This article is a glimpse into methods being developed to address problems ranging from computational physics to computer vision.

12 The Multibeam Fabry-Perot Velocimeter: Efficient Measurement of High Velocities

Using the multibeam Fabry-Perot velocimeter designed at Livermore, stockpile stewardship scientists are obtaining accurate, easy-to-read data about weapons materials accelerated to ultrahigh velocities.

Research Highlights

20 High-Tech Tools for the American Textile Industry

24 Rock Mechanics: Can the Tuff Take the Stress?

\section{Patents}

\section{Abstracts}

Printed in the United States of America

Available from

National Technical Information Service

U.S. Department of Commerce

5285 Port Royal Road

Springfield, Virginia 22161

\section{UCRL-52000-96-7}

Distribution Category UC-700

July 1996

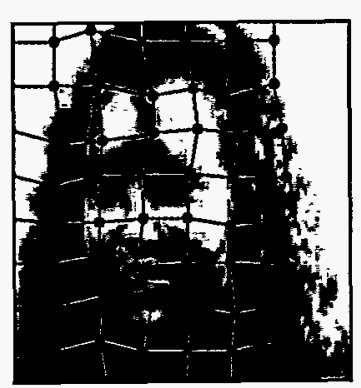

Page 4

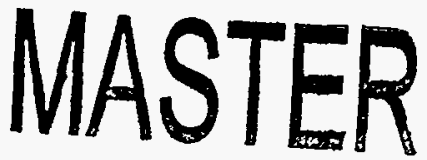

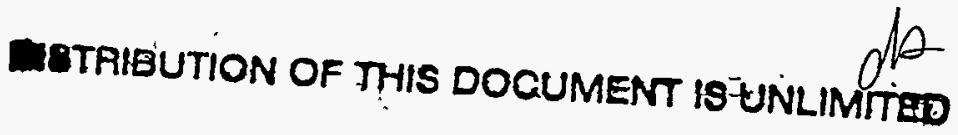

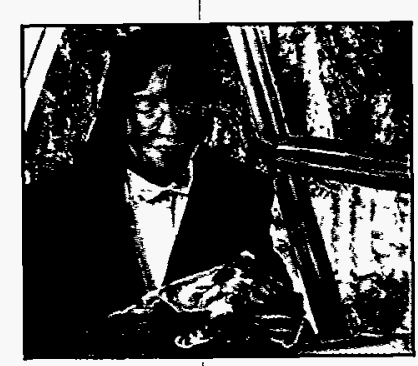

Page 20 


\section{MIR being adapted to detect land mines}

Land mine detection may become the newest use for Lawrence Livermore's popular Micropower Impulse Radar technology, already licensed for a variety of commercial applications because its cost, size, and power consumption are dramatically less than conventional radar's.

In April, the Defense Department's Defense Nuclear Agency awarded the Laboratory $\$ 300,000$ to adapt the technology for detection of metal and plastic land mines. During the initial year of funding, Lab researchers will develop and test a prototype system and evaluate different radar frequencies for land mine detection. If its efforts prove successful, the MIR land mine project could run for two more years and receive an additional $\$ 1$ million in funding.

Toward the conclusion of the project, the Laboratory expects to work closely with private industry to prepare for large-scale manufacturing of land mine detectors developed under the project. One detector envisioned is a handheld, lightweight sweeper that would be waved back and forth about 10 centimeters above the ground. Other configurations include robotic and vehicle-mounted systems.

Contact: Steve Azevedo (510) 422-8538 (azevedo3@ IInl.gov).

\section{Lab to supply adaptive optics for Keck II}

Keck II, the new 10-meter telescope atop Hawaii's dormant Mauna Kea volcano, soon will receive an adaptive optics system being developed by Lawrence Livermore and Keck scientists. The adaptive optics system, an outgrowth of the Lab's Guide Star research, will rapidly correct for image blurring due to turbulence in the Earth's atmosphere. This system will thus allow the Keck II telescope to see almost as clearly as if it were in space.

In May, Livermore Director Bruce Tarter was on hand in Hawaii for the dedication of Keck II. Lawrence Livermore's Large Optics Diamond Turning Machine was used to create Keck II's infrared secondary mirrors. The Laboratory also has about a half dozen research projects that will rely on the Keck scopes.

Contact: Claire Max (510) $422-5442$ (max1@IInl.gov).

\section{Bubbles may explain $\mathrm{x}$ rays from neutron stars}

Powerful $x$-ray emissions from rotating, magnetized neutron stars may be governed by the turbulent motion of "photon bubbles" rapidly rising from the surface of such stars.

That theory, first proposed in the 1980s, appears to be supported by early observations from a new NASA satellite, the Rossi X-Ray Timing Explorer. If further confirmed, the theory could provide expanded insight into the extraordinary conditions that exist on and near the surface of a neutron star, a once-large star collapsed to a radius of about 10 kilometers (6 miles).

Theoretical astrophysicists Richard I. Klein and Jonathan Arons fashioned the photon bubble theory more than a decade before joining observational astrophysicist Garrett Jernigan, who was involved with development of the NASA satellite. Before the satellite's launch, the trio made a major effort to predict what it would see.

Because it is so difficult to test, astrophysical theory is often debated for years before gaining or losing favor as evidence slowly accumulates. But in this case, NASA's satellite provided a remarkable range of confirmatory data only weeks after an updated version of the theory was published.

The theory and its confirming satellite observations were highlighted in April during a high-energy astrophysics meeting in San Diego. Leading the discussion was Klein, who works at Lawrence Livermore and in the Astronomy Department of the University of California at Berkeley. Contact: Richard I. Klein (510) 422-3548.

\section{DOE to extend University of California contracts}

The Department of Energy (DOE) has announced it will enter into negotiations with the University of California to seek a fiveyear extension of the contracts to manage Lawrence Livermore, Lawrence Berkeley, and Los Alamos National Laboratories. The present contracts expire September 30, 1997.

"The University's record of scientific achievement at the three laboratories and its reputation for 'world class' science are unparalleled," said DOE Secretary Hazel O'Leary, in announcing the decision.

In response, Lawrence Livermore Director Bruce Tarter said he sees "the University providing unique experience and continuity at a time of sweeping change, particularly during the critical phase of the nation's development and implementation of the science-based nuclear stockpile stewardship program."

The stockpile stewardship program is a key element in President Clinton's commitment to maintain a safe and reliable nuclear weapons stockpile without underground nuclear testing. Livermore and Los Alamos are the United States' laboratories responsible for the nuclear components of the stockpile.

In recognizing the University's long-standing relationship with the federal government, President Clinton said, "Over the last five decades, the University of California made an enormous contribution to our success in winning the Cold War. We look forward to working with the University of California to promote both our economic and national security."

Contact: Lawrence Livermore Media Relations Office (510) 423-3118. 


\section{DISCLAIMER}

Portions of this document may be illegible in electronic image products. Images are produced from the best available original document. 


\section{DISCLAIMER}

This report was prepared as an account of work sponsored by an agency of the United States Government. Neither the United States.Government nor any agency thereof, nor any of their employees, makes any warranty, express or implied, or assumes any legal liability or responsibility for the accuracy, completeness, or usefulness of any information, apparatus, product, or process disclosed, or represents that its use would not infringe privately owned rights. Reference herein to any specific commercial product, process, or service by trade name, trademark, manufacturer, or otherwise does not necessarily constitute or imply its endorsement, recommendation, or favoring by the United States Government or any agency thereof. The views and opinions of authors expressed herein do not necessarily state or reflect those of the United States Government or any agency thereof. 


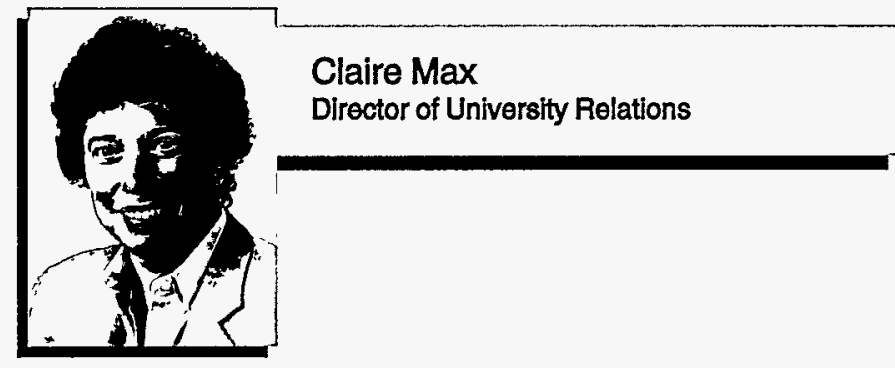

1 HE Lawrence Livermore National Laboratory has unique facilities and expertise that are being used to address problems of interest to the broad U.S. research community. One of the ways to make these resources available-and to accomplish other important goals-is the University Relations Program. In fact, two of the articles in this issue of Science \& Technology Review relate to the work of this program.

In March 1995, Director Bruce Tarter created the University Relations Program to coordinate activities with the common themes of university collaborations, student involvement, and programs sponsored by the University of California at the Laboratory. Our mission is to contribute to the intellectual vitality of the Laboratory, the University, and industrial communities by fostering cooperative basic and applied research. Our organization consists of three "umbrellas." The first covers the University of California Institutes; the second includes programs with the UC Office of the President, the LLNL Education Program, and the Partnership for Environmental Technology Education; and the third covers programs for which we serve as liaison.

The Institutes program began in the early 1980s at Lawrence Livermore. As the usefulness of the initial Institutes became firmly established, others were founded. These Institutes complement, rather than duplicate, ongoing programs at Lawrence Livermore.

Currently, the Laboratory's Institutes program consists of the Institute of Geophysics and Planetary Physics (I was the founding director in 1983), the Center for Accelerator Mass Spectrometry, and the Institute for Scientific Computing Research. The latter is the subject of the article starting on p. 4 of this issue. A fourth Institute, devoted to Laser and Plasma Science, is due to begin operation soon. These Institutes provide a focus for collaborations with the nine UC campuses as well as with many other universities around the country. The results of one of these collaborations-the search for Massive Compact Halo Objects-were reported in the April 1996 issue of Science \& Technology Review.

Under the second umbrella, the LLNL Education Program contributes to systemic improvement in math, science, engineering, and technology education to ensure a skilled, diverse workforce and to enhance scientific and technical literacy. The Education Program has components that involve teachers and students and promote public awareness and technology education. For example, the research highlight on rock mechanics on p. 24 gives some details on the successes of one program in this area.

Our programs with UC's Office of the President include UC-Directed Research and Development funds, which encourage scientific exchange between UC and Lawrence Livermore; Campus Laboratory Collaborations, a new initiative in which the UC Office of the President selects proposals for collaborative research between UC's campuses and national labs; and the UC Presidential Post-Doctorate Program, which encourages minorities and women to conduct world-class research at one of UC's nine campuses or three DOE laboratories.

The Partnership for Environmental Technology Education is a national nonprofit organization designed to foster training in environmental technologies at the community college level. The partnership links the technical resources of national labs, federal and state agencies, professional societies, and private industry with participating community colleges. This network, piloted originally in five western states, now consists of six regional partnerships serving all 50 states and has 400 participating colleges.

The third umbrella-our liaison programs-includes liaison with the UC Davis Department of Applied Science, the UC Davis Center for Image Processing and Interactive Computing, the Glenn T. Seaborg Institute of Transactinium Sciences, and Lawrence Livermore's Student Policy Committee.

As the Laboratory's missions continue to change with the evolving world situation, collaborative research and education take on increasingly important roles. The Lab is moving from its traditional mode of working on projects where all the relevant expertise resides in-house, to areas such as nonproliferation, biotechnology, health care, energy, and environmental research-areas in which many other institutions have expertise as well. In a collaborative environment, more of this power can be brought to bear on programs of strategic importance to the Laboratory and the nation. As the University and DOE consider the extension of the Laboratory's contract, our research collaborations provide a good example of the clear mutual benefit in continuing this important and successful relationship. 


\section{Frontiers of}

The Laboratory's newly reorganized Institute for Scientific Computing Research fosters collaborati research in advanced computing techniques. Rece, Researchin

work is laying the foundations for innovativ and sometimes startling methods in

computational physics, massively parallel Advanced processing, computer vision, the modeling of human joints, and a range of other applications.
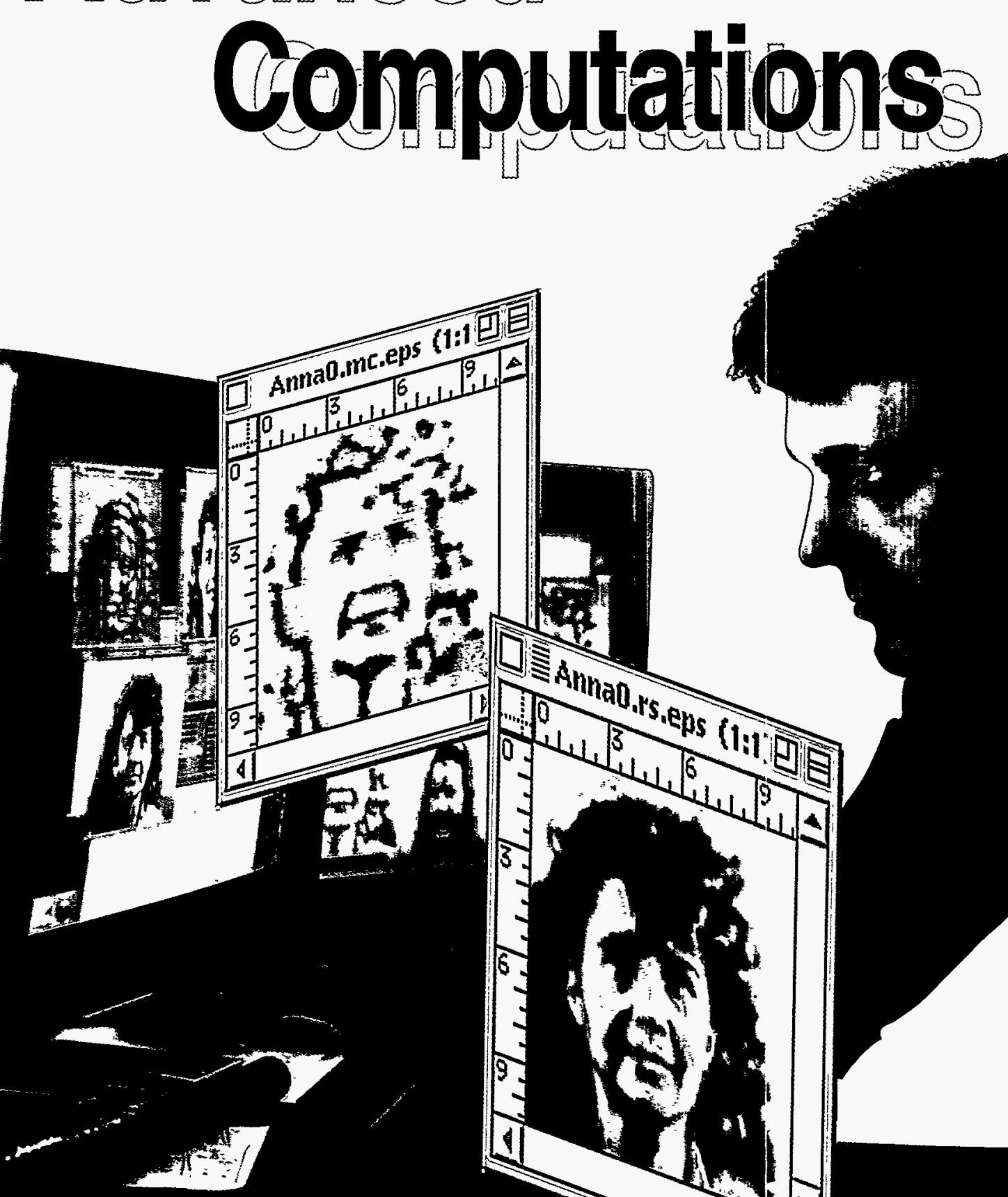
massively parallel processing, real-time object and motion recognition systems, and improved models of human joint dynamics.

\section{Grid and Particle Hydrodynamics}

As part of the ISCR, the Center for Computational Physics (formerly within the Plasma Physics Research Institute) develops simulations that help researchers study the behavior of plasmas, which are highly or completely ionized gases, and other physics phenomena. One new algorithm, Grid and Particle Hydrodynamics ( $\mathrm{GaPH}$, pronounced "gaff"), is a computational tool for studying the complex behaviors of a plasma or a gas. $\mathrm{GaPH}$ was developed to help scientists and engineers understand more about the chemistry of systems with complex geometries and to do so at far less cost than that of other methods. We can understand much of its purpose through a simple example of the kind of problem $\mathrm{GaPH}$ was designed to address.

Figure 1 shows data about two localized gas "puffs" that expand into one another, colliding and interpenetrating. Figure 1a is a snapshot of two sharply defined spikes of gas that are slightly separated in space. Most of the gas particles are moving slowly, but a few are about to move quickly in one direction or another (those with large negative or positive velocity). It is like a snapshot of two large groups of people in Grand Central Station-some people are standing still, others are strolling, some are rushing to catch a train, but all are temporarily frozen in time. Then the two gas puffs "splash" into each other. Figure $1 \mathrm{~b}$ does not show collisions; Figure $1 \mathrm{c}$ is a simulation with collisions included. When gas puffs interpenetrate, many steepening pressure waves are formed that can become complex and turbulent. Simulating those turbulent waves is precisely the type of problem that Laboratory scientists need to address in studying $z$-pinches (structures used to generate $\mathrm{x}$ rays) and interpenetrating plasmas in National Ignition Facility targets and in weapons systems.

The current approach at the Laboratory is to use a fluid treatment (hydrodynamics codes) to study these systems. But when these systems are driven hard by external forces, a pure fluid treatment fails to recover important

Figure 1. Example of a simulation using $\mathrm{GaPH}$. (a) Two gas puffs are initially separated by a small distance. Over time, the gas puffs interpenetrate. GaPH simulates the distribution of particles in space at an instant in time (b) without collisions or (c) with collisions. Notice that with collisions, the faster expanding particles from each side collide and pile up in the center, and GaPH captures the detail.These simulations were accomplished with fewer than $700 \mathrm{GaPH}$ particles.

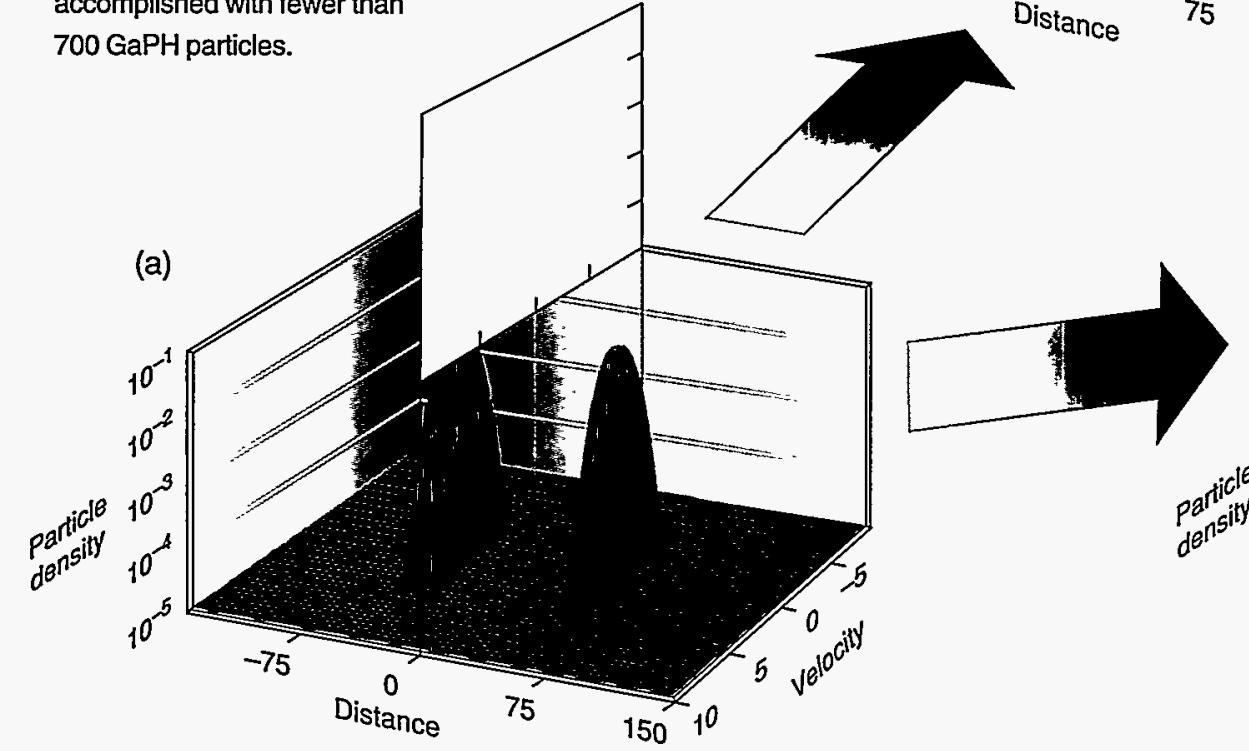

(b)
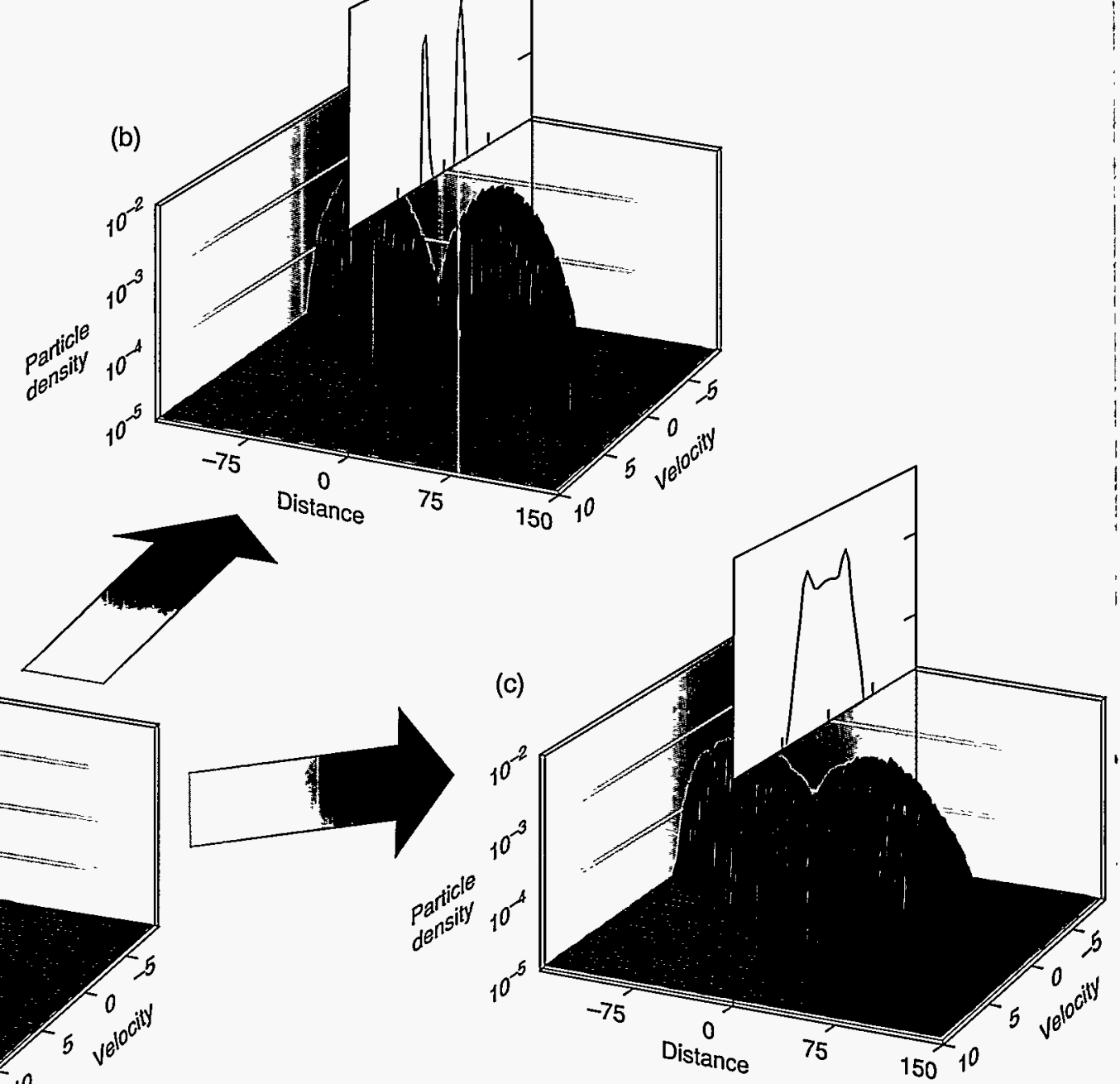

Science \& Technology Review July 1996 
features. Mixing and turbulence build and grow so fast that collisions do not relax the system back to consistency with fluid models.

A common alternative that overcomes some of these difficulties is the particle-incell (PIC) method, which groups many similar particles together into macroparticles and follows their interactions using discrete time steps. Even so, today's computers can follow only a small fraction of the events of interest. A PIC collection can hint at the essential features, but it takes experienced eyes to see signals in the noise.

$\mathrm{GaPH}$ is a better tool for understanding gas and plasma behavior. $\mathrm{GaPH}$ can model systems in which gases or plasmas either do not collide (Figure 1b) or do collide (Figure 1c) with one another. The code can be used to reconstruct the distribution of real particles at all points in space at any time of interest.

$\mathrm{GaPH}$ starts with a relatively small number of "smart" particles, each of which is a lump of fluid representing many (perhaps billions of) real gas molecules. Each GaPH representation has velocities in all directions based on the internal dynamics within the lump. Over time, individual superparticles expand due to their internal energy (pressure) and velocity.

$\mathrm{GaPH}$ is unique in that it continuously allows new superparticles to be "born" so that they will be available where interesting things are happening (Figure 2). Conversely, superparticles with overlapping properties can be merged. By eliminating redundant representations, $\mathrm{GaPH}$ wastes less computational effort and focuses more efficiently on the most relevant collisions or events. For example, a onedimensional $\mathrm{GaPH}$ simulation needs only 400 superparticles rather than the 20,000 macroparticles required for a standard PIC problem. The important points are that $\mathrm{GaPH}$ allows investigators to spend their computer resources on those parts of a problem that require the most scrutiny, and $\mathrm{GaPH}$ can account for the interactions that escape standard fluid treatments.

Even though $\mathrm{GaPH}$ is a new concept, it already appears to be the best tool to address interpenetration in turbulent systems with low rates of collision. The next step is to extend $\mathrm{GaPH}$ to threedimensional representations and to introduce more realistic physics.

\section{Electromagnetic Modeling}

The Center for Computational Physics is also a center of excellence for the computer modeling of low-frequency electromagnetic phenomena (often called Darwin models after their originator) in plasmas and magnetic materials. In these models, high frequencies (light waves) are neglected, thus eliminating considerable computational effort. Such numerical simulations are important for many Laboratory and industrial applications of plasmas.

Laboratory programs are concerned with the behavior of plasmas in etching and deposition processes, magnetic fusion, laser fusion, and other areas including defense. Plasmas can be simulated with fluid, PIC, or GaPH techniques, but each one requires a suitable way to calculate the electromagnetic fields that interact with the charged particles of plasma. The ISCR is developing Darwin models that
Figure 2. Imagine that a simulated superparticle (a) is a sugar cube containing billions of atoms. As the cube melts and spreads out (b), GaPH continuously adds new particles to the simulation (c) to account for what is happening at the edges.

(c)

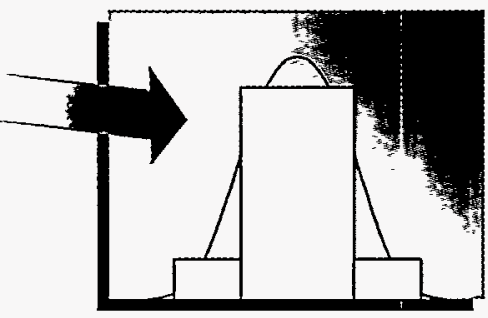

provide the fields for any of these techniques. ${ }^{1}$

In semiconductor wafer etching, an important plasma application, researchers need to design reaction chambers that properly confine plasma, and they need to optimize antennas that can generate a uniform plasma of maximum density across the wafer surface (Figure 3 ). The ISCR has developed models that describe this process, simulating both resistive heating (similar to current through a wire) and stochastic heating, which depends on the distribution of plasma particles. Institute researchers have concentrated on extending their models to address three-dimensional problems.

Many other applications can benefit from the same types of computational methods. One example is high-speed flywheels that can serve as electromechanical batteries (see the April 1996 issue of Science \& Technology Review). Another application is in the magnetic recording industry, which has developed a new, giant magneto-resistive material. This material allows changes in resistivity (the detection of which results in a "read") to be caused by a much smaller change in a magnetic field. Thus, a "bit" can be localized in a much smaller area, enabling information to be packed more densely than on present-day magnetic media. The interactions behind this concept (those 
between low-frequency magnetic fields and induced electric fields) are a perfect application for the ISCR's Darwin models.

\section{Massively Parallel Processing}

A popular view is that the future of supercomputing will depend on massively parallel computers. The arguments are persuasive, so what is the delay? For one thing, compilers (programs that convert scientific programming language into machine language) do not yet use all the capabilities of the newest hardware. But even when compilers catch up, users still have to reorganize their algorithms and the way they think about solutions to realize the promise of massively parallel computing.

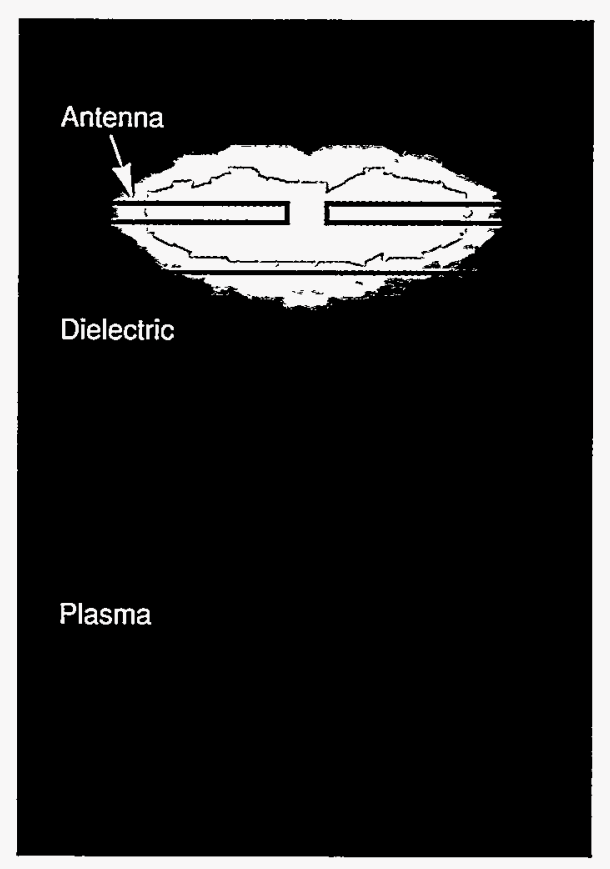

Figure 3. To process wafers as semiconductors, antennas generate plasmas by heating electrons. In this simulation of a two-dimensional plasmaprocessing chamber, the contours are the magnitude of the electric field driven by the antenna. Yellow represents high electric field intensity; blue indicates low electric field intensity.
Massively parallel processing (MPP) systems can have $100,1,000$, or even more microprocessor-based central processing units (CPUs). During a complex calculation, a problem is broken down into tasks or fragments. The difficulty is that, at some point, the processor assigned to a given task needs information computed elsewhere. In many cases, all parts of the system must talk to every other part before a solution is reached. Slightly stretching the point, it is as if every U.S. citizen had to talk with every other citizen before a candidate was elected President. MPP users worry about data layout across all the processors, synchronization between tasks, data transfer rates, and many other issues.

Three years ago, Institute researchers began exploring MPP techniques to solve linear systems that are the backbone of many codes used at the Laboratory and other institutions. This work involves collaborations with faculty and students at the University of California campuses at Davis and Los Angeles and with LLNL researchers outside the Institute.

The Institute developed a new linear system to implement alternating-directionimplicit (ADI) methods but found that it also is useful in other areas. ADI codes split a big computational problem into a series of independent linear systems. Rather than giving an entire "line," or part of the problem, to each processor, each line is split over several processors, and adjacent segments of neighboring lines can now be given to the same processor. Equally important, the domain structure-the spatial partitioning of problem parts to each processor-remains unchanged during the entire solution process.

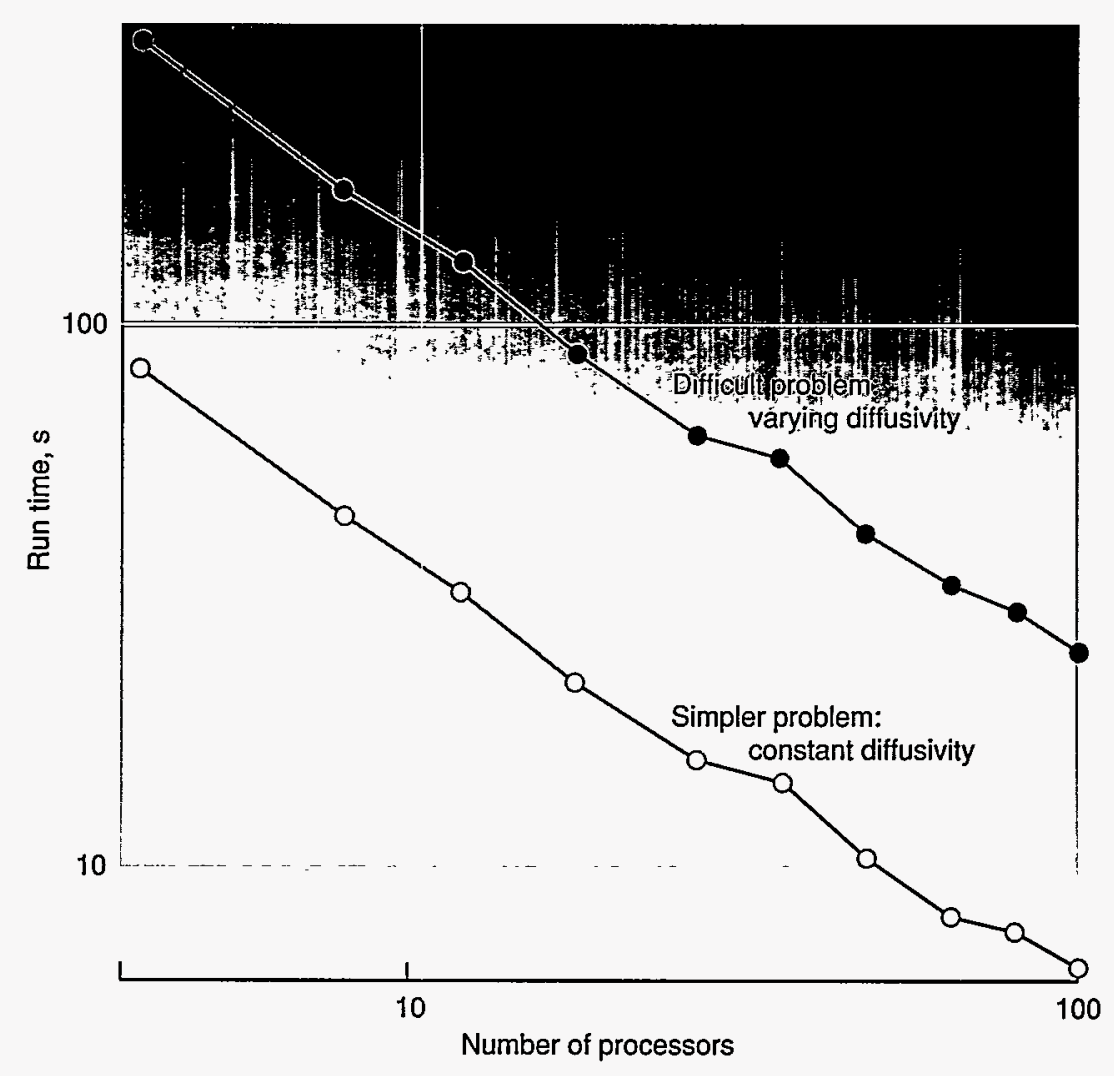

Figure 4. The curves show results for a three-dimensional, dynamic altemating-directionalimplicit (ADI) solution of the steady-state diffusion equation involving 864,000 unknowns. Note the large decrease in time as the number of processors increases. 
The Institute's new methods have several advantages (see Figure 4). The part of a problem associated with each processor can be tailored to minimize the information exchange between processors, which is a particularly important issue for PIC or fluid models. The methods make it possible to apply plasma and magneticmaterial codes in two and three dimensions with relatively high resolution. It will also be easy to apply the new concepts as MPP multiprocessor technology continues to mature.

\section{Curved-Boundary Modeling}

Many computer simulations use irregular mesh elements to represent structures with curved boundaries. In some cases, mesh points can move with a structure so that the model follows the motion of the structure.

Orthogonal meshes consist of a set of straight lines that intersect at right angles at mesh points. A close look at a curved boundary represented this way reveals a jagged representation (Figure 5a). Although this approach is adequate for certain problems, the computer representation of electromagnetically driven particle motion near such boundaries is incorrect and often unacceptable.

Livermore's ISCR has developed a new embedded curved-boundary (ECB) method that offers the utility and flexibility of unstructured meshes while retaining the speed and user-friendly characteristics of orthogonal meshes. Curved boundaries are embedded within an orthogonal mesh, making it possible to model realistic curved boundaries on a computationally convenient mesh. The advantages (Figures $5 b$ through $5 d$ ) include much quicker solution of the differential equations required in the vicinity of a curved boundary. As with other boundary models, embedded curved boundaries can also be moved at the user's discretion to follow the motion of a structure.

This work is closely connected to the Institute's other efforts in that the ECB method builds more capable (a) Stair-step vs embedded curved boundaries

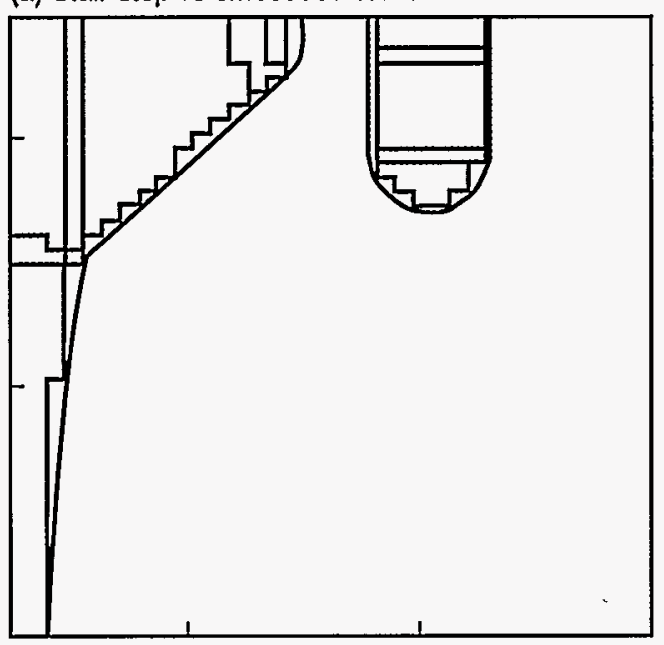

(c) lons emitted from anode

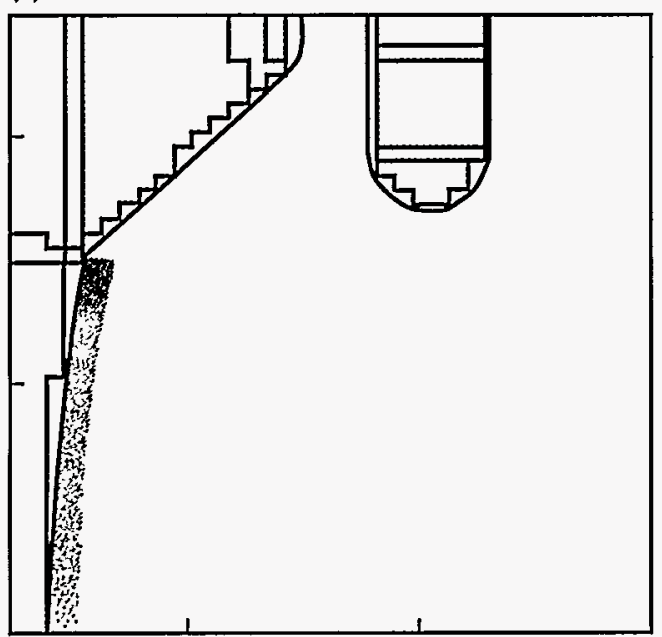

(b) Contours of electrostatic potential

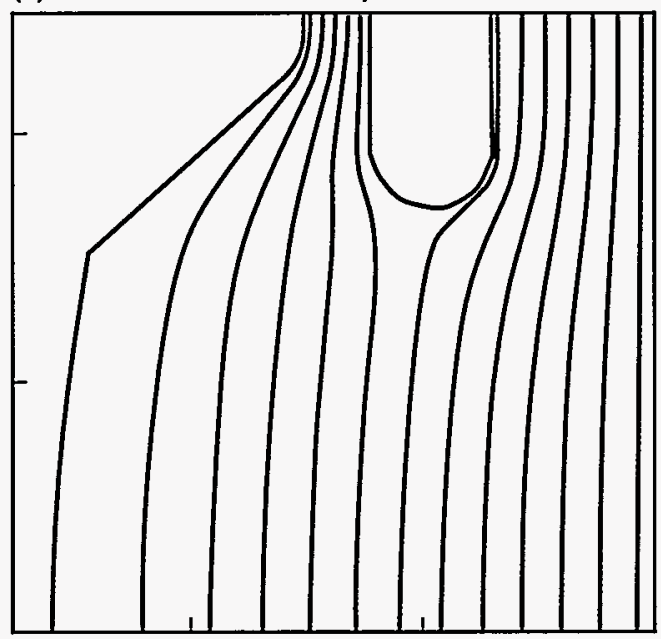

(d) lons focused by cathode

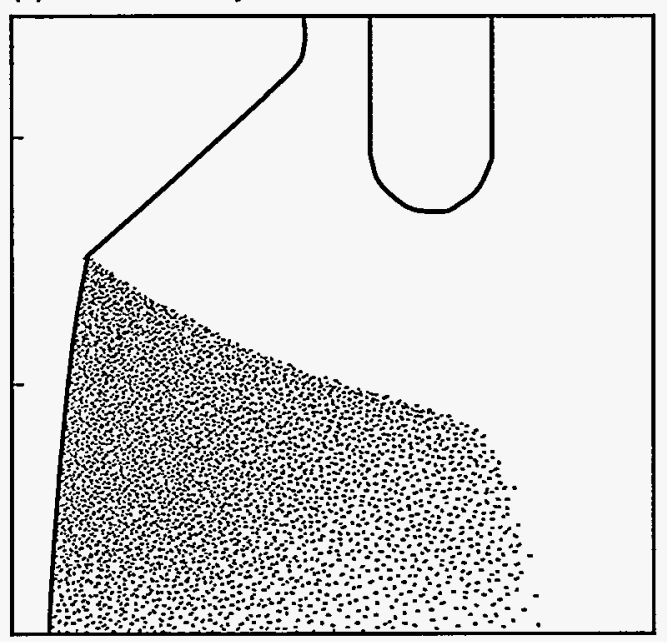

Figure 5. Cross sections of a typical ion injector. (a) Compared to an orthogonal mesh, embedded curved boundaries more accurately represent the actual electrode surfaces. (b) Calculated contours of electrostatic potential using curved boundaries. lons are (c) emitted from the curved anode and (d) subsequently focused by the extraction cathode. 
(a)

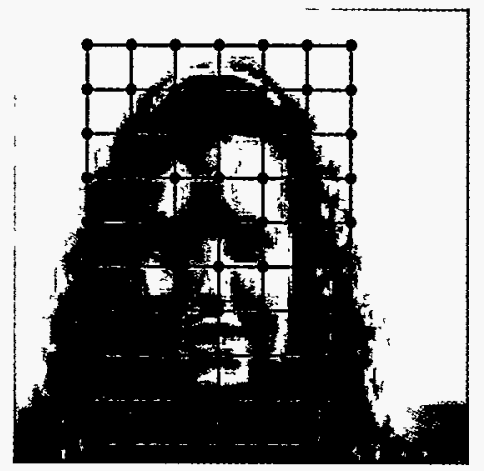

(b)

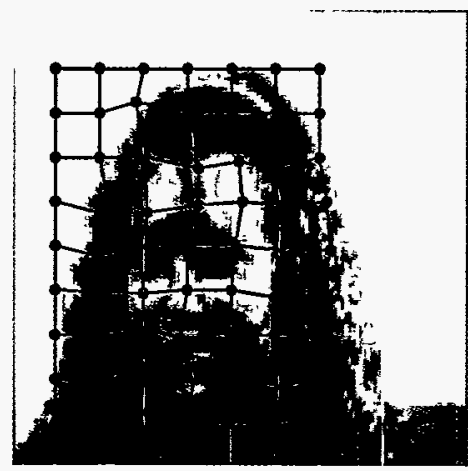

Figure 6. (a) KEN outlines a face to be matched with a grid overlay, here shown as a rectangular grid for clarity, and stores it in its memory. (b) Matching is determined by how closely a new image fits the grids stored in the database.

representations of the differential equations in the vicinity of curved boundaries. The result is that the ECB method can be seamlessly added to the newly improved capability in massively parallel processing. Taken together, $\mathrm{GaPH}$, Darwin models, and ECB methods are adding considerable power to the Laboratory's modeling strength and to the move toward massively parallel implementation.

\section{Computer Vision}

Using computers to recognize objects has enormous possibilities in the era of the information superhighway.

Automated object and motion recognition can be applied in security and surveillance, medical, defense, and telecommunications applications as well as in a host of other areas. Computerized object recognition would be an invaluable tool for searching image databases. Face recognition could, for example, be used to verify credit cards or other valuable property. An autonomous robot with a recognition system could access places or perform tasks that are impractical for humans.

The ISCR developed a near-real-time face-recognition technology, KEN, which was previously reported on in Energy \& Technology Review. ${ }^{2}$ As shown in
Figure 6, KEN extracts information about a face in the form of a grid marked with features and stores this model in memory. To recognize a face, KEN compares all face models in its database to the unknown face. After statistical evaluation of similarities and differences, the system rejects poor matches and selects a qualified match if one is found. Using a database of several hundred faces, KEN can identify up to $98.5 \%$ of the faces correctly. Industry contacts from TRW and Intel (among others), law enforcement agencies in Europe and California, and the FBI have expressed interest in the technology.

The ISCR's computer vision group is extending KEN to include much larger databases, to organize the databases by comparing stored face models with each other, and to recognize other object classes, such as footprints, signatures, and graphics. They also recently began developing a motion-recognition system featuring a new motion-sensitive silicon retina. This work is a logical extension of $\mathrm{KEN}$, which is based on a comparison of two images. Motion recognition tracks the distortion or changes occurring in a succession of several images.

The ISCR's approach to computer vision incorporates advanced, modular, mix-and-match components in hardware and software. The components are based on artificial neural networks and neuromorphic engineering concepts, which mimic the structure and activities of the brain. The Institute's work at the forefront of computer-vision research attempts to mimic a type of motiondetection process found in biological visual systems. More specifically, computers can imitate the way specialized neurons in the retina respond to a moving target but do not react when a target is stationary.

ISCR researchers can use either a charge-coupled device (CCD) camera or analog silicon-retina chips as the input sensor (or "eye") for a computer. These chips, developed by a research group at the California Institute of Technology, have improved dynamic range in difficult lighting conditions compared to a CCD camera.

The motion-recognition system being developed will combine a high-resolution silicon retina, a motion-sensitive chip, devices for data capture and processing, and object-oriented software components. Figure 7 shows some early results from tests of a motion-sensitive chip. A prototype system will be up and running by the fall of 1996.

An important spinoff of motion analysis involves data compression of video sequences. The new method developed by ISCR researchers uses motion-assisted segmentation to yield a higher data-compression factor (up to 350 to 1) of generic video test data with fewer errors than other methods. This method could contribute a component to the MPEG-4 Standard currently under development by the Motion Picture Expert Group (MPEG). MPEG-4 specifically aims at low-bitrate and wireless communication.

\section{Biomechanical Modeling}

ISCR researchers in collaboration with the Laboratory's Engineering Directorate are also developing computational models of the structure 
and function of human joints. In this work, ISCR researchers begin with very high-resolution scans from individuals and use surface extraction and finiteelement techniques to create highly detailed, accurate models of joint dynamics. A three-dimensional, nonlinear, finite-element model (NIKE3D, developed at LLNL for engineering problems) allows the ISCR biomechanics group to address biological problems realistically. Researchers can assess interactions among different types of tissue-including bones, ligaments, tendons, and muscle-when they assign mechanical properties and physiological loads to each structure within a joint.

Biomechanical modeling will lead to a better understanding of repetitive strain injury, degenerative joint diseases, and traumatic injury. A current focus is on applying the joint models to solve problems in the orthopedic industry, specifically to extend the quality and life span of prosthetic joint implants. This biomechanical modeling effort will be the topic of a research highlight in the September issue of Science \& Technology Review.

ISCR work has also included finding a way to noninvasively monitor blood oxygen in real time and developing Sisal, a functional language that simplifies the programming of parallel supercomputers.

The goal of the Sisal Project is to have the system software automatically manage the machinery and allow the programmer to focus on the problem and its solution. By speeding up the coding process and supporting existing codes written in other languages, ISCR researchers developed a way to make portable parallel computing more practical and affordable than ever before. Two spinoffs of this project are the Massively Parallel Input/Output Project, now in its third year, and the High-Performance Functional Computing Project. In short, Institute researchers do more than simply refine old methods or apply
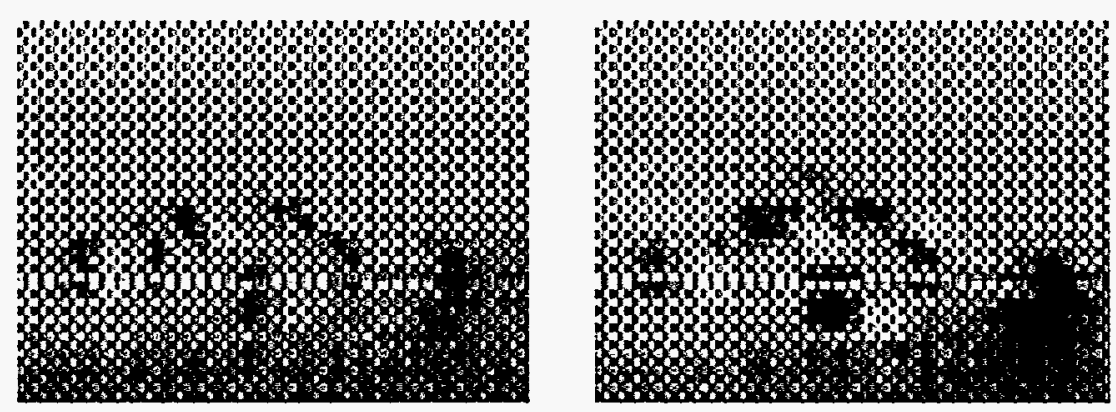

Figure 7. An almost stationary target (left) yields no signal. Faster motion of a model car (right) traveling from left to right increases the signal seen by a motion-sensitive silicon retina designed at the California Institute of Technology.

them efficiently to new hardware; it is not enough to do a job several times faster on a better machine. Rather, the Institute seeks alternative ways to represent physical information, to bridge the gap between computer science and scientific computing applications, and to reach solutions. When a given project is successful, an entirely new program may be born.

Key Words: advanced computer modeling methods-alternating-direction-implicit (ADI), embedded curved-boundary (ECB), grid and particle hydrodynamics (GaPH), KEN, lowfrequency electromagnetic (Darwin); computer vision; Institute for Scientific Computing Research (ISCR); massively parallel processing (MPP).

\author{
References \\ 1. D. W. Hewett, "Low-Frequency \\ Electromagnetic (Darwin) Applications \\ in Plasma Simulation," Computational \\ Physics Communications 84, 243 \\ (1995); M. R. Gibbons and D. W. \\ Hewett, "The Darwin Direct Implicit \\ Particle-In-Cell (DADIPIC) Method \\ for Simulation of Low Frequency \\ Plasma Phenomena," Journal of \\ Computational Physics 128, 231 \\ (1995). \\ 2. "KEN Project: Real-World Face \\ Recognition," Energy \& Technology \\ Review, UCRL-52000-94-10 (October \\ 1994), pp. 22-23.
}
For further information contact
Dennis W. Hewett (510) 422-5432 (dhewett@IInl.gov).

\section{About the Team}

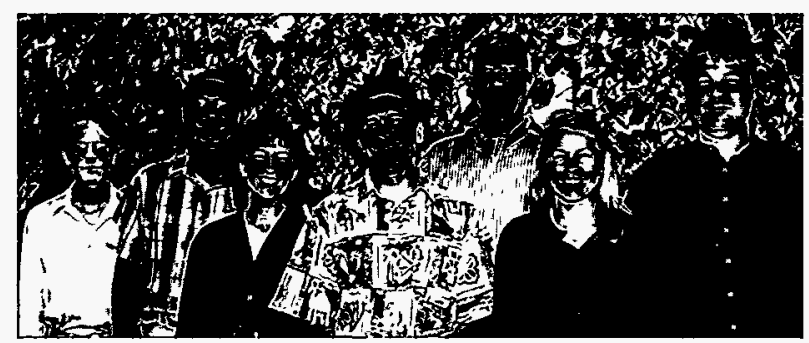

Hewett, Louann S. Tung, anc collaborative research in advanced inside and outside the Laboratory and is currently focusing on inovative computing methods in computational physics, massively parallel processing computer vision, and biomechanical modeling, among others. 
standard method for measuring speed that we all learned in school is to divide distance by time. If we measure velocity rather than just speed, we can obtain information on direction. But how do we measure velocities of as much as 3,000 meters per second over distances as short as 2 or 3 millimeters? And why would we want to take such measurements?

As part of our responsibilities for scientific stewardship of our nation's nuclear weapons stockpile, Lawrence Livermore National Laboratory performs a variety of experiments to study the velocity and other motions of materials accelerated by explosives, gas guns, and electrically accelerated plates. We use a number of diagnostic tools, including

a Fabry-Perot velocimeter, to analyze these experiments. These experimental data are then used to certify the safety and reliability of our nuclear stockpile without the validation provided by underground tests.

In our studies, we seek information on the equations of state of various materials, the behavior of materials subjected to strong shock waves and other hydrodynamic phenomena, the explosion process, and the behavior of projectiles and targets upon and immediately after impact. For example, we may look at how materials respond to various hypothetical scenarios. Our ability to measure continually changing velocities is important because shock waves, for instance, cause objects to have velocities that are not constantthe object may accelerate, then decelerate, and then accelerate again, all within a few microseconds.

A typical experiment might involve testing the behavior of a high-explosive material that has been shaped into a disk and coated with a half-millimeterthickness of copper. Several diagnostic tools would be used to study the high explosive, one being a Fabry-Perot velocimeter to measure the velocity of the copper after the high explosive is detonated from the back. Depending on the experiment, we have from only 1 to 100 millionths of a second to obtain information, from detonation to the point where dust and debris from the explosion get in the way of data collection.

We compare the results from tests such as these to the predictions from our hydrodynamic computer modeling codes to determine whether the codes make adequate predictions. If the codes do not match test results, such data as material strengths can be changed in the codes. In the absence of a nuclear test program, this validation process must continue until we have full confidence in our modeling codes.

Obtaining accurate measurements is thus of critical importance. But efficient use of budgeted funds is equally important. For example, we could do one experiment five times to collect five comparable data sets for validation purposes. But then we would have the cost of the experiment times five plus the problem of replicating the experiment precisely, which is extremely difficult. We might or might not in fact collect five comparable data sets from those five experiments (the perennial apples and oranges problem). It would be better to obtain all five data sets at

\section{Livermore scientists have designed a multibeam Fabry-Perot velocimeter that is proving invaluable to the Laboratory's science-based stockpile stewardship mission. It provides} high-resolution, continuous data records about the behavior of weapons materials

accelerated to velocities as high as 3,000 meters per second. 
the same time, saving time and money and ensuring that we are comparing apples with apples when we study the data. But a traditional Fabry-Perot system, one of the best instruments available for obtaining continuous data on high-speed velocities, was able to take only one or sometimes two sets of measurements at a time. We could use five velocimeters to obtain five simultaneous data sets, but their cost would be very high, and the equipment would take up much space and be difficult to maintain and operate.

Scientists at Lawrence Livermore's High Explosives Applications Facility have been working for over 15 years to improve our capability to gather accurate information about high velocities.

Building on that experience, we recently combined several newly developed devices with a high-power laser, a Fabry-Perot interferometer, and five streak cameras to create a multibeam Fabry-Perot velocimeter (Figure 1). We have split the laser light into five individual beams with very high efficiency and have devised the technology for keeping the five light beams distinct. Collecting five data sets simultaneously from a single experiment using one interferometer is now a reality.

\section{Single-Beam Velocimetry}

For many years Lawrence Livermore National Laboratory has been using laser interferometry to make high-speed velocity measurements. Interferometry operates on the principle of the Doppler effect, which is the apparent difference between the frequency at which sound or light waves leave a source and the frequency at which they reach an observer, caused by the relative motion of the observer and the wave source. It is the Doppler effect that causes the apparent pitch of a passing train to rise as the train approaches (creating shorter wavelengths or higher frequency) and to drop as the train moves away (creating longer wavelengths or lower frequency).

This same principle may be applied to the experiment described on p.13.

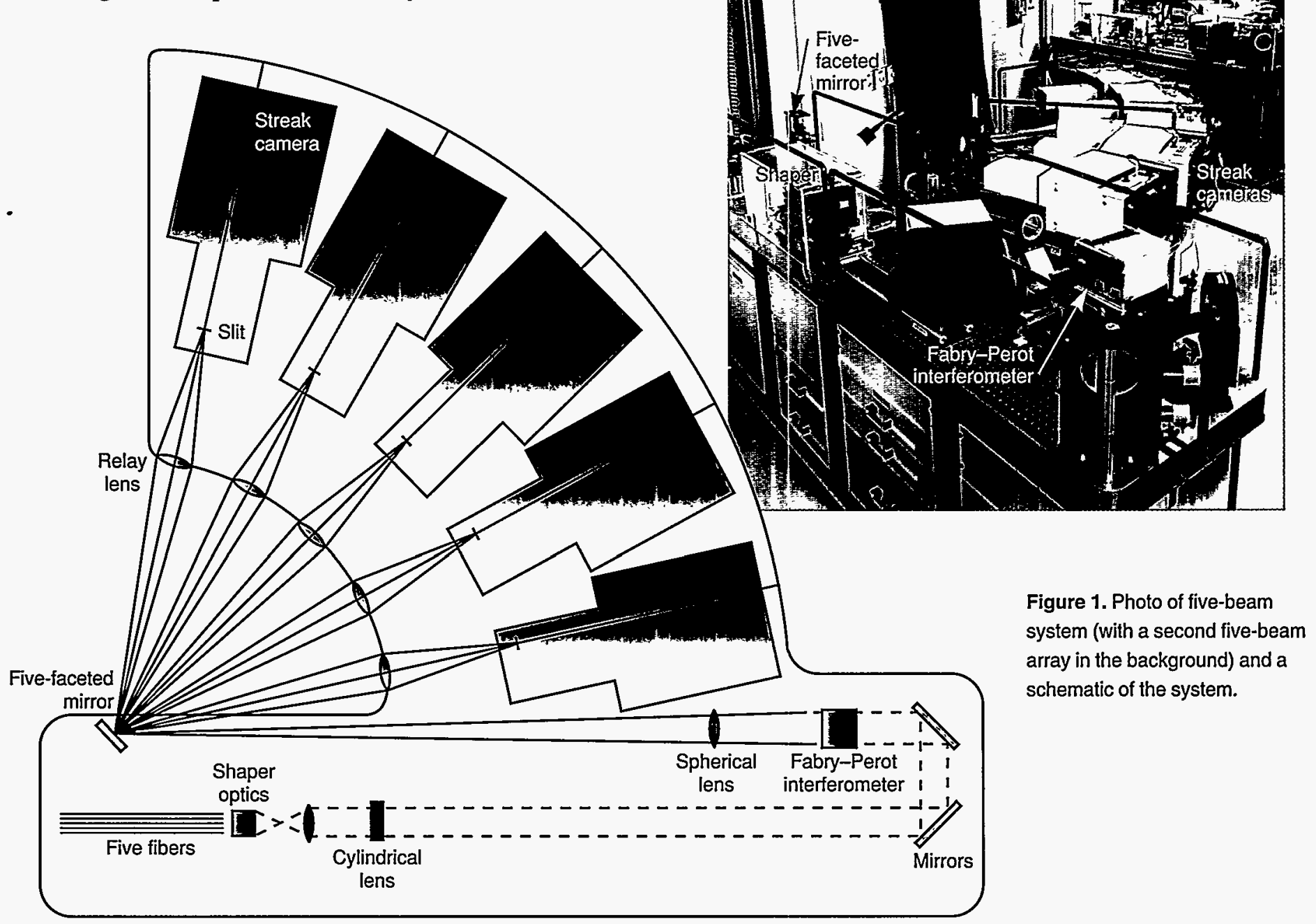


We can shine laser light on the copper as it is being accelerated toward the light and collect some of the light that reflects off the copper. The velocity of the copper as it accelerates but before it disintegrates after detonation can be inferred by measuring the slight changes in the wavelength of the reflected light as the copper moves toward the unmoving light source. Because light waves are so small (about 2,000 wavelengths per millimeter), using them as a measuring device provides extremely high sensitivity. The laser's frequency is $6 \times 10^{14}$, or 600 trillion oscillations per second. Fifteen billion oscillations will occur in an experiment as brief as 25 microseconds.

The reflected light is sent through an interferometer, which splits the light source into several beams, sends them along different paths, and then combines them in an "interference" pattern. (In physics, interference refers to the increased amplitude of a wave that results from superimposing two or more waves of the same or nearly the same frequency.) Very precise velocity measurements may be made from this interference pattern.

The Fabry-Perot interferometer is almost 100 years old. Today, the Laboratory's version consists of a pair of round slabs of special glass, about 2 centimeters thick and about 7 centimeters or more in diameter. They are ground and polished flat to approximately one two-hundredth of a wavelength of light (or about threemillionths of a millimeter). The glass is made highly reflective by about 20 coatings of dielectric material evaporated onto its surface. The separation between these precisely parallel mirrors depends on the demands of the particular experiment and can range from a few millimeters for some applications to as much as 15 centimeters.

Before entering the Fabry-Perot, the reflected light passes through a cylindrical lens (see Figure 2), which converges the light vertically while maintaining the beam's horizontal dimension. Concentrating the light in this manner results in more usable light inside the interferometer.

The Fabry-Perot's first mirror is almost perfectly reflective (99.5\%) and has a 0.75-millimeter-wide stripe of the dielectric coating removed from across its middle. The second mirror is typically about 93\% reflective. Light enters the Fabry-Perot through the stripe in the first mirror and bounces back and forth between the mirrors about 50 to 100 times, creating the same number of weak transmitted beamlets parallel to each other and staggered in time. Because of the almost perfect reflectivity of the first mirror, virtually no light is lost back out the front mirror, except for a small amount that goes back through the stripe. The reduced reflectivity of the second mirror allows the beamlets to pass through it.

Each set of 50 to 100 beamlets travels a path from the first mirror, through the second mirror, and through a spherical lens to that lens's focal plane. Figure 2 shows that the first of the beamlets travels the shortest path, the second bounces once on the striped mirror before passing through the second mirror, the third bounces twice, etc. If the difference in the lengths of the paths of the successive beamlets is an integer number of wavelengths (e.g., 10,002 or 300,000 ), then the beamlets are all in phase and will interfere with (that is, reinforce) each other when they reach the spherical lens's focal plane. The

(a)

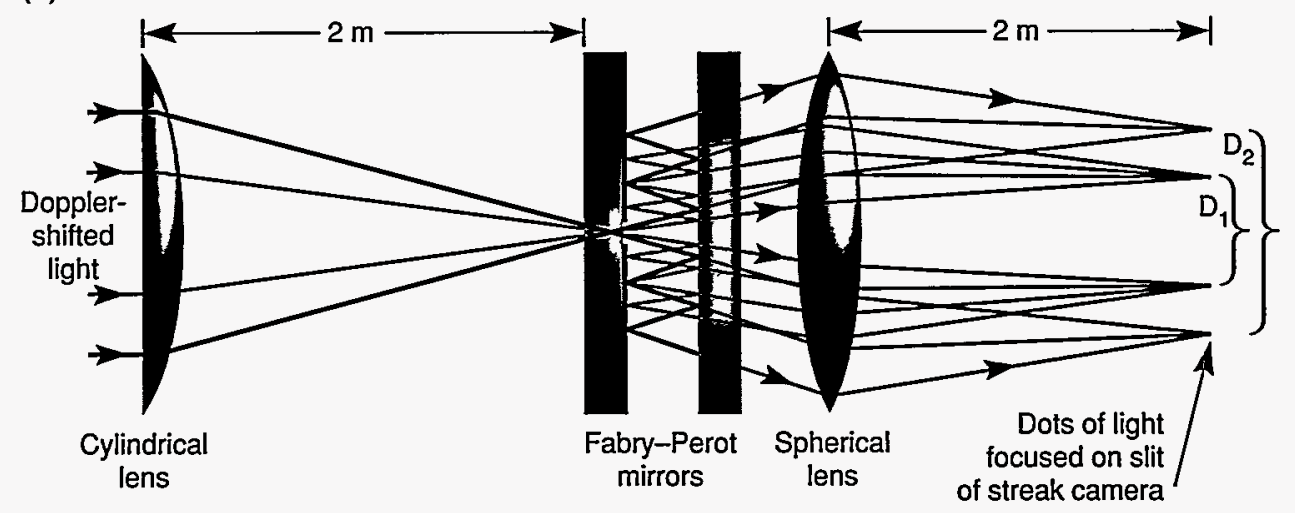

(b)

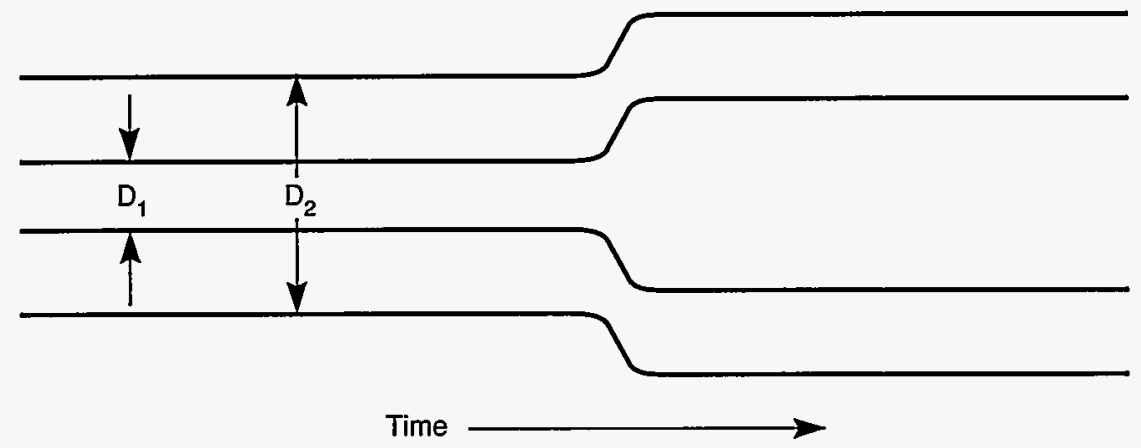

Figure 2. (a) A top view of the Fabry-Perot velocimeter system from the cylindrical lens to the slit in the streak camera. The interference pattern of bright dots $-D_{1}$ and $D_{2}-$ is recorded on the streak camera. (b) A hypothetical streak camera record shows what happens to $D_{1}$ and $D_{2}$ when acceleration occurs. Velocities are determined using a formula based on measurements of the separation between the dots. 


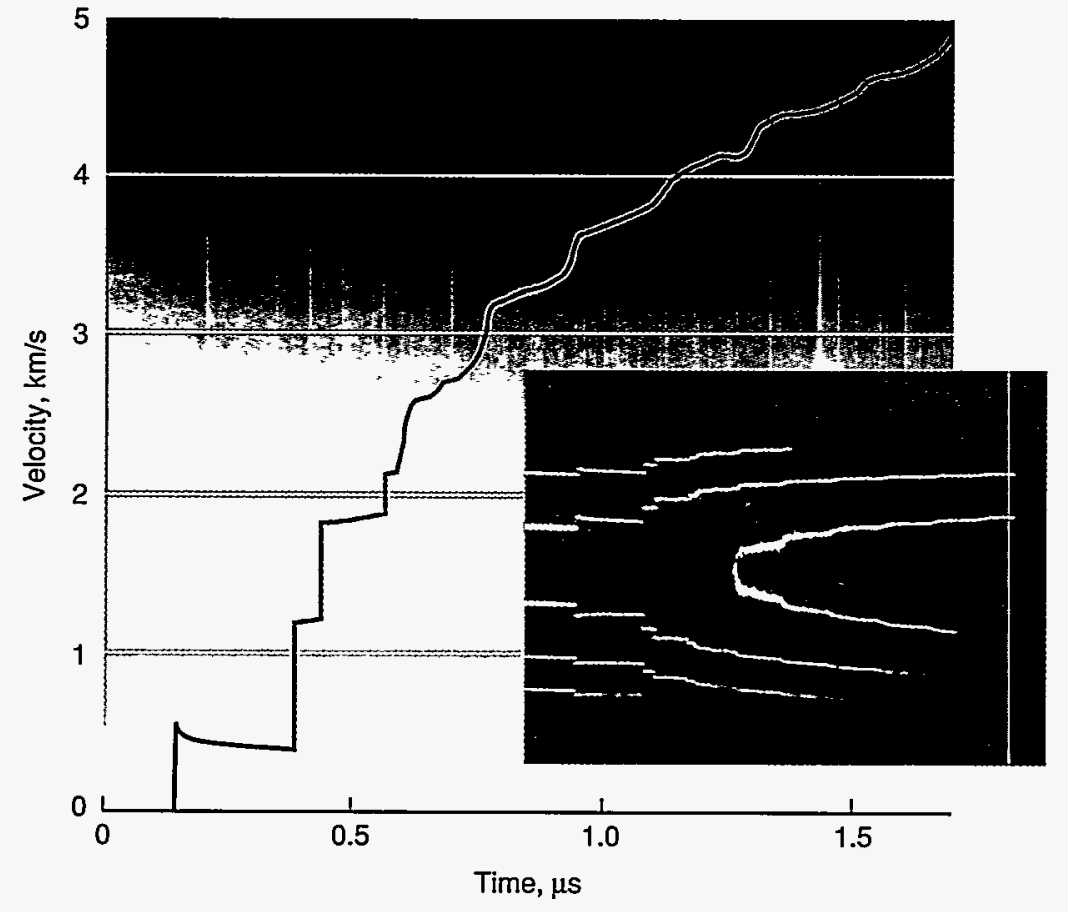

Figure 3. A time sweep as recorded by a streak camera (inset) translates into the velocity vs time record shown on the graph.

interference pattern of each set of beamlets creates a bright dot.

Only certain combinations of the reflected light's wavelength and angle of reflection and the distance between the Fabry-Perot mirrors create resonant angles, which cause the beamlets from a given beam to have the same phase and to interfere constructively with one another. The combination of the cylindrical lens and the narrow stripe in the first mirror assures that virtually all of the light entering the Fabry-Perot is at vertical angles, creating enough resonant angles to create six or eight bright dots.

As the copper accelerates, the reflected light's wavelength decreases, the resonant angles therefore increase, and the separation between the bright dots increases. This image of dots, known as an interference fringe, enters an electronic streak camera through a narrow vertical slit. In the streak camera, the image is swept across a piece of film (see Figure 3).

From the width and number of the fringes, extremely sensitive measurements can be made of the velocity history of the copper as a function of time, starting before acceleration began and continuing as long as conditions permit. The record of velocity versus time can be inferred using a formula that is based on measurements of the separation between the dots. Simple measurements of dot separation can be done with a magnifier and scale, and more precise analysis is done by digitizing the record.

\section{Our Multibeam System}

To collect five simultaneous sets of data, we cannot simply run five beams through a Fabry-Perot interferometer. Whereas the one-beam output is a series of bright dots with high velocity resolution, five beams would produce smeared records with low resolution. To obtain the high resolution required for precise velocity measurements, special optics are required to shape the five beams and keep them distinct.

There also needs to be a good way to split the laser light into five beams and to get the five reflected beams back to the instrumentation. The old method of shining the laser beam through a tilted mirror with a small hole in it works for one beam but would be unwieldy for more. There is also the problem of directing multiple outputs from the Fabry-Perot interferometer to several streak cameras.

\section{The Laser}

We use a frequency-doubled, neodymium-doped yttrium-aluminumgarnet (Nd:YAG) laser that produces a very pure green light for 80 microseconds. "Pure" color means that there is no change in the light's wavelength or frequency even over a distance of more than 10 meters and that the frequency is stable to 50 parts per billion for the duration of the experiment. Precise velocity measurements require that the light remain in phase across a distance equal to the total number of roundtrip "bounces" between the Fabry-Perot mirrors, or 5 to 20 meters depending on the separation between the mirrors.

A beam splitter divides the laser beam into five individual beams, which are carried to the experiment on fiber-optic lines. We have designed special probes, each of which holds two fiber-optic lines-one to carry light to the experiment and another to carry reflected light back to the instrumentation.

Figure 4 is a series of photographs of the experiment described on page 13. The five beams are visible as the disk begins to explode.

\section{Keeping Five Beams Separate}

As the 1- to 100-microsecond experiment takes place, the reflected 
light travels into the instrument room and through the "shaper," which is the heart of our multibeam system. The shaper is a complex of lenses of Laboratory design that compresses the fiber images horizontally by a factor of 4 (from 100 micrometers to 25 micrometers) while maintaining the vertical dimension of 100 micrometers (see Figure 5). Even with this compression, we can preserve the same angular divergence of the light at the image as it had at the experiment. Now the five sets of dots are well separated relative to their width, and no light that could be used is wasted. (In single-beam as well as multibeam velocimetry, some light is wasted because the light comes in on a larger fiber than the instrumentation can use.) The shaper sends the light from the separate fibers into the velocimeter at slightly different horizontal angles, so that any given horizontal angle corresponds to only one fiber. The five beams can thus be distinguished from one another later when the streak camera results are analyzed.

The shaper can actually handle ten beams, although to date it has handled just five because of space limitations for streak cameras.

(a)

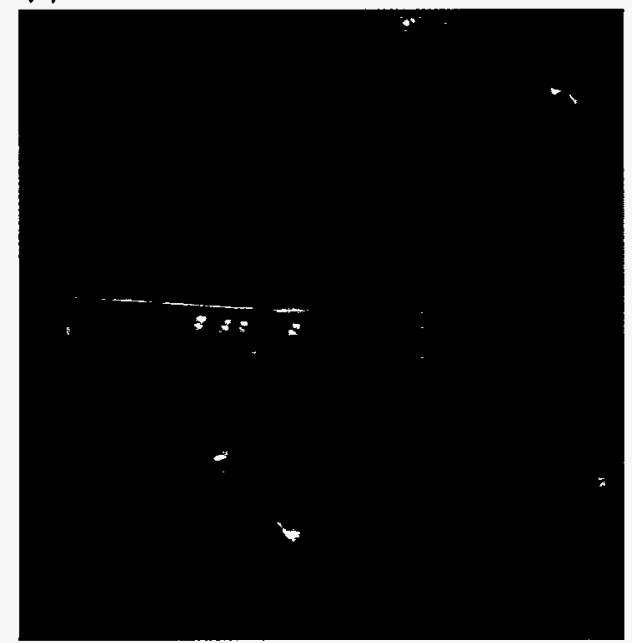

\section{Getting Beams to Cameras}

Our five-beam system creates five columns of six to eight bright dots. The columns, each of which comes from a specific incoming fiber, are only 0.9 millimeters apart horizontally at the focal plane of our spherical lens. We have designed and constructed a fivefaceted mirror about 3 centimeters high, with the center of the three middle facets just 0.9 millimeters apart. The five facets are separated in angle by 7.5 degrees, allowing the five streak cameras to be placed 15 degrees apart. Each streak camera views one column of the faceted mirror through a large relay lens.

\section{"Foolproofing" the System}

Our work on the Fabry-Perot velocimeter system has not been limited to pushing five beams through a single interferometer. We have made other improvements that make it an even more useful diagnostic tool whose records are now virtually foolproof to analyze.

\section{A Referee to Verify Results}

When a shock wave arrives at an object, the object's velocity can increase very rapidly, often too fast for our system

(b)

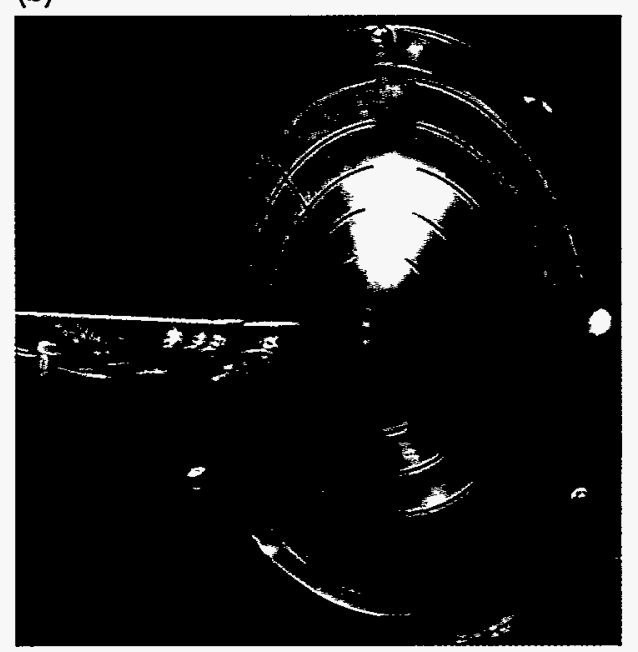

Figure 4. In photos of the experiment described on $p .13$, the five laser beams are visible on the copper, but the probes themselves are out of the field of view. The visible bracket holds timing pins that short out when the copper material hits them. That timing information tells scientists the shape of the experiment as it explodes. Photo (a) was taken before detonation and (b) was taken 8 microseconds after detonation as the shock waves have reached the fourth ring. In (c), taken 14 microseconds after detonation, the dark material near the edge is the copper coming apart. The white glow around the edge of the disk is gas from the high explosives.

(c)

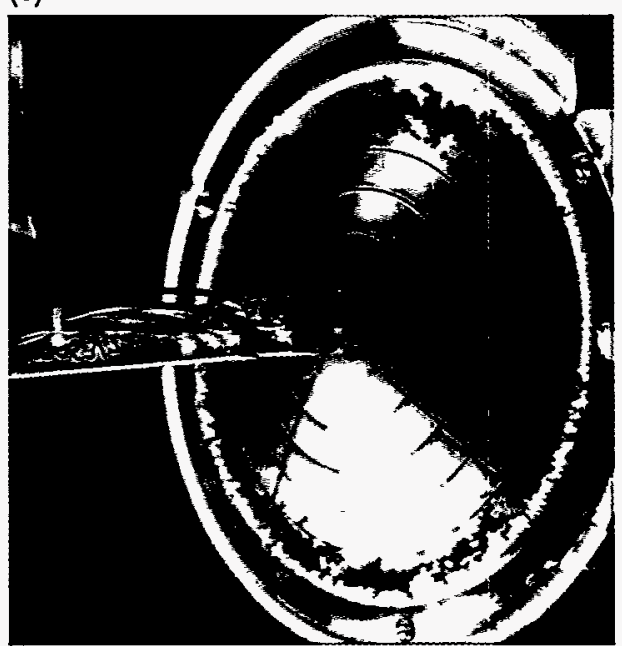


to follow. Every time the velocity increases by a fixed amount (for example, by 0.6 millimeters per microsecond, a value that will vary depending on the distance between the Fabry-Perot mirrors), the dot pattern repeats itself. This means that if the increase is too rapid to follow continuously, not one but several possible velocities can be inferred. Often common sense and experience allow us to infer the correct velocity. But in unusual experiments, this easy inference is not possible, and we therefore devised the dual-cavity interferometer, which has two mirror distances within the same unit.

With some of the light inside the interferometer traveling one distance and some a smaller distance, we obtain two sets of interference fringes for each beam coming from the cylindrical lens. Each streak camera thus records two sets of fringes (see Figure 6). This second, "referee" set of fringes is a significant aid in resolving the uncertainty in reading rapid acceleration data. Analysis of the fringe overlap shows that there is always, at any velocity, an adequate set of separated fringes to correctly interpret the experimental data.
In our latest version of the dual-cavity interferometer, we create the second cavity by suspending a piece of very-high-quality glass, about 2.5 centimeters square and 7.5 centimeters high, between the FabryPerot mirrors. It is relatively inexpensive and can be inserted or removed as experimentation needs demand.

\section{Customized Streak Cameras}

A relay lens images the dots from the faceted mirror to the vertical slit of the streak camera, which sweeps and intensifies the image across a piece of film, providing the record of velocity versus time. The electronics and housings for the cameras were custom made at the Laboratory to obtain special features not available commercially. For example, our cameras can be made to sweep the dot image at one speed for part of the record and then at another speed during the remainder of the record. This feature allows better time resolution for particular parts of the record. We have also installed a special time fiducial system, which provides both bright and dim marks in the field of view to allow absolute timing references between cameras.

\section{Using the Incoming Beam Twice}

For some experiments, we want the streak cameras to operate at very fast sweep rates to obtain fine velocity details but also to sweep more slowly to record the entire motion. With the dual sweepspeed streak cameras described above, we can do this using as many beams as there are cameras. However, by using ten cameras for five beams, we can get more detailed information.

We can have two cameras recording an experiment at two different speeds by making use of the fact that light comes into our multibeam system from a larger fiber size than the interferometer and streak cameras can use. After the reflected light goes through the shaper, the excess light enters a system of mirrors that carries it up, over, and down to another table set up with a second interferometer and five more streak cameras. This way, the first camera on the second table records slowly the same velocity history that the first camera on the first table is recording more rapidly. We have found that this method makes a far more efficient use of available light than a beam splitter would, and it has been successfully used on dynamic experiments.

\section{The Power of Velocimetry}

Fabry-Perot velocimetry provides unambiguous records of very complex situations. For example, in some experiments rather like the one described on p. 13, evaporated gold

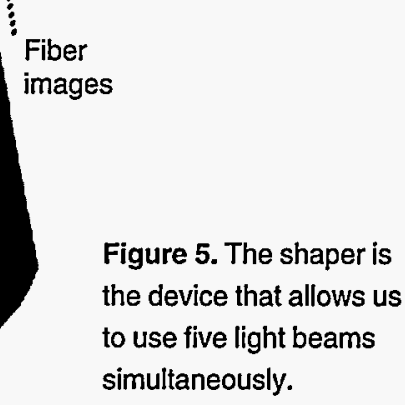

Figure 5. The shaper is the device that allows us to use five light beams simultaneously.

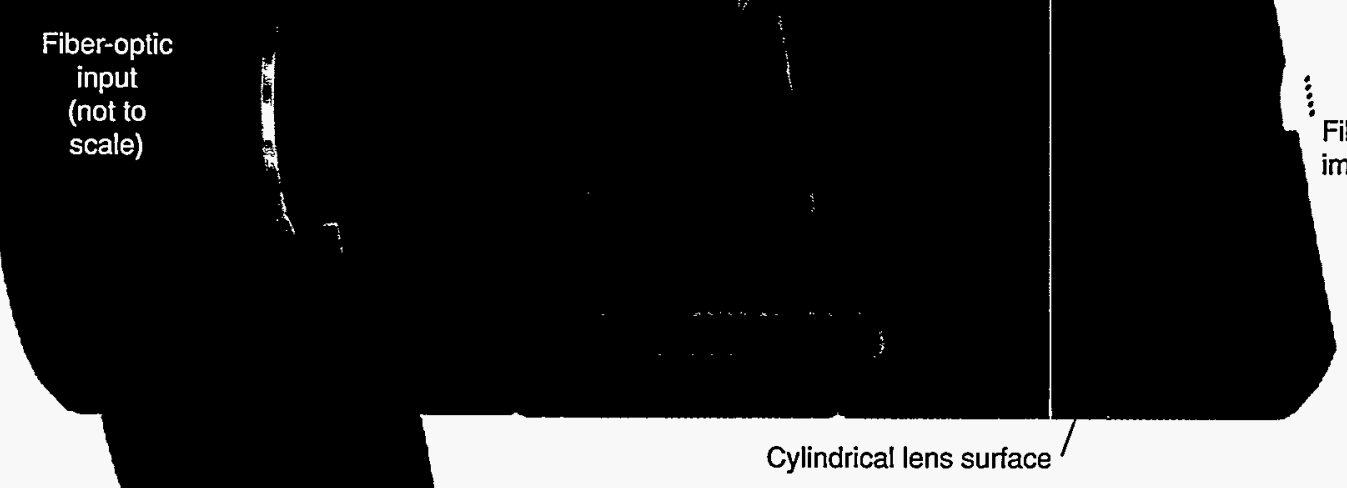


layers are applied to surfaces for higher reflectivity. After the shock wave arrives, the surface often decelerates, and sometimes part of the gold pulls away from the surface, a process known as spallation. If illumination by the probe covers areas of the surface where gold has spalled and areas where it has not, we get two different velocity histories on the same camera. There may also be unshifted (no change in wavelength) light from non-moving surfaces such as a vacuum window, dust, or uncoated glass, in addition to shifted light from moving surfaces. Fabry-Perot interferometry can handle all of these situations on a single, easily read record.

The Fabry-Perot velocimeter is unique in providing information on continuous velocity from both simple and complex experiments. The multibeam Fabry-Perot velocimetry system is a powerful, practical diagnostic tool whose results can be quickly and easily verified. The value of the multibeam system has been recognized beyond the boundaries of the Laboratory: two five-beam arrays will soon be installed at the Nevada Test Site for non-nuclear testing.

We presently have a ten-beam capability, with two five-beam arrays. We are in the process of expanding to four five-beam arrays, which will give us 20 simultaneous sets of measurements, at approximately half the cost of 20 singlebeam Fabry-Perot velocimeters. As the system is further developed and expanded, it will become an ever more useful tool, with improved time and velocity precision.

With the multibeam system producing more meaningful data than has been available to us in the past, we can make our modeling codes increasingly accuratea necessity for effective stewardship of our nuclear stockpile.

Key Words: Fabry-Perot interferometry, optical velocimetry, optics, streak cameras.

For further information, contact

David Goosman (510) 422-1630. (a)

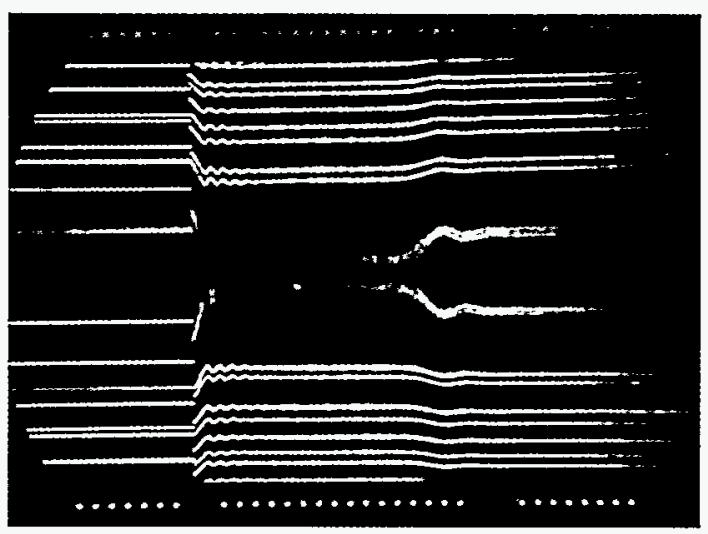

Figure 6. (a) An example of a streak camera record from an earlier version of our dual-cavity Fabry-Perot interferometer. (b) An example of data analysis using three different estimates of the "jump" in the dot pattern when rapid acceleration occurs. Without the second set of fringes, the scientists would not know which is correct. The overlap of the center two curves shows it to be the correctly estimated velocity.

(b)

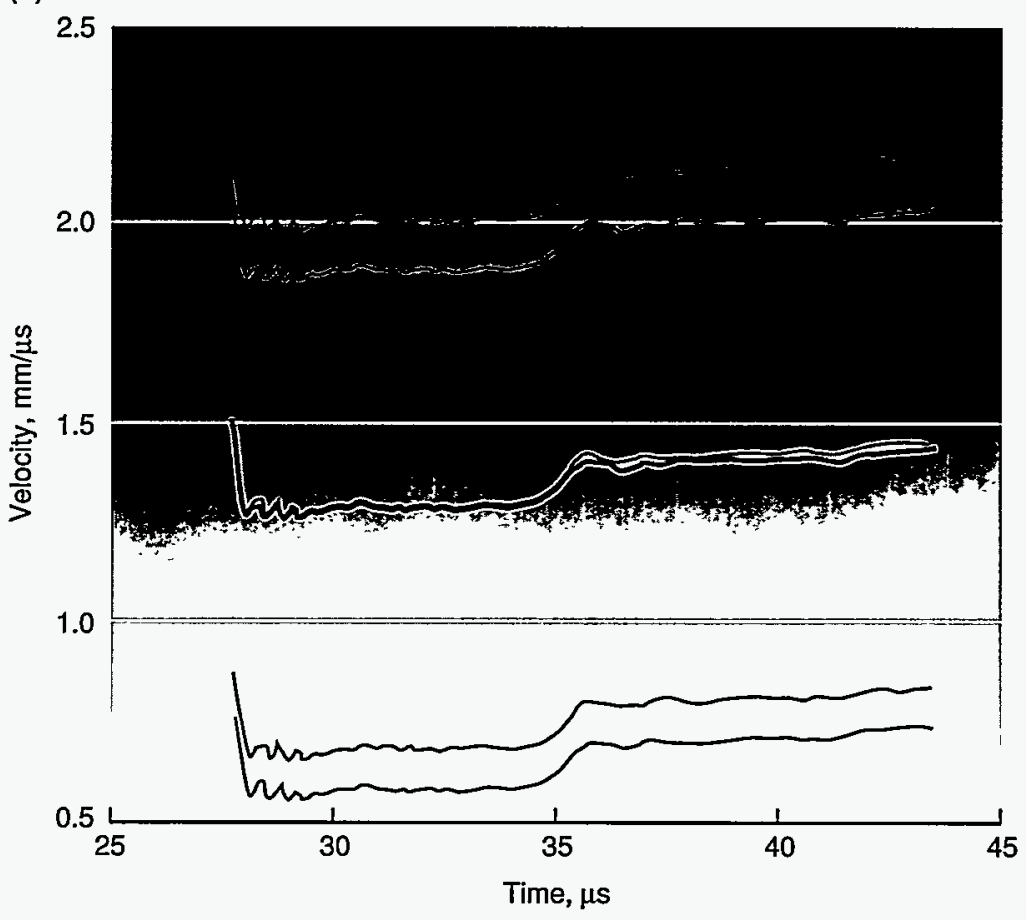

\section{About the Scientist}

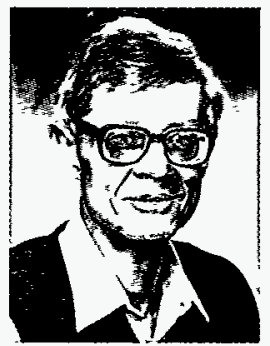

DAVID R. GOOSMAN joined the Laboratory in 1974 and has been Group Leader for Advanced Experiments Projects since 1980. He received a Ph.D. in Nuclear Physics from California Institute of Technology in 1967, and from 1967 to 1969, he was a post-doctoral fellow there. From 1969 to 1974 , he carried out nuclear physics experiments at Brookhaven National Laboratory. He has published more than 60 articles on nuclear physics, radiography, and optical velocimetry. 


\section{High-Tech Tools for the American Textile Industry}

$\mathbf{T}$

HE textile industry in the United States is

huge-it employs more people than any other manufacturing sector and accounts for the most consumer sales among durable and nondurable goods. The U.S. leads the world in growing cotton and is very strong in the production of many kinds of fibers and finished cloth. But most sewing of finished apparel has shifted overseas, and overseas competitors are cutting into our predominance in fiber production and weaving. Over the last ten years, 400,000 American jobs have been lost to this intense overseas competition.

At first glance, a CRADA (Cooperative Research and Development Agreement) between the American textile industry and the Department of Energy's national laboratories might seem an odd match. It was born during a 1992 DOEsponsored workshop on critical industries, when representatives from textile firms and DOE laboratories realized how much they had to offer each other. The laboratories have developed technologies in energy, environmental cleanup, and national defense that can help the U.S. textile industry improve its competitiveness in worldwide markets and create jobs as well by increasing quality, reducing costs, improving responsiveness and production times and by reducing the environmental impacts of manufacturing operations. Through its involvement in this CRADA, the DOE can obtain more information about market demands and needs in areas of communications, networked information, imaging, sensing, tagging and tracking, and environmental cleanup.

This partnership, known as AMTEX, began in 1993 as a collaborative program among DOE and eleven of its national laboratories and several textile research organizations. The entire textile industry is represented, including the retail, sewn products, textile manufacturing, and fiber production sectors.

Lawrence Livermore National Laboratory's contribution to the AMTEX partnership falls into five areas:

- Demand-Activated Manufacturing Architecture-For this project, Livermore is developing the first-of-its-kind client authentication software, which is discussed below.

- Computer-Aided Fabric Evaluation-Livermore-developed sniper detection technology is being applied to this project, which is discussed below. 


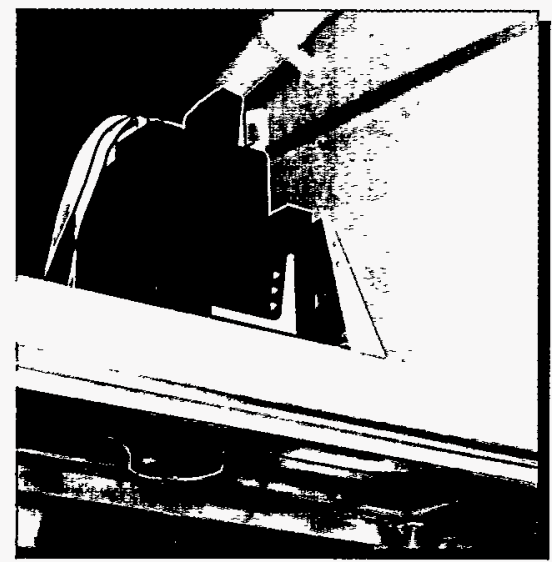

A camera (inset) is mounted at the top of this A-frame structure, which is part of the demonstration unit for computer-aided fabric evaluation. Behind the A-frame is a closeup of the fabric that summer student Jessica Bayliss is inspecting.

- Electronically Embedded Fingerprint-Livermore worked on developing miniature electronic devices for permanent identification and inventory management. Manufacturers will be able to read and write information about size, color, style, process history, country of manufacture, etc. on a device the size of a grain of rice. This "fingerprint" may replace the bar code, which is not permanent and is limited in the amount of information it can store. A larger version of the fingerprint was originally developed by Livermore for permanent identification of weapons and other treaty-controlled items.
- Textile Resource Conservation-Livermore is developing and testing new processes to conserve the huge amounts of water used to dye and finish fabrics. Using less water in processing also means less downstream water treatment. - Rapid Cutting of Textiles-Using its expertise in lasers, Livermore has developed a very-short-pulse, solid-state laser to replace the blade that has been used for decades to cut garment components from piles of fabric. The laser is faster than the blade and could be used for rapid custom cutting. The system is particularly useful for cutting very strong fabrics like Kevlar, which is used for sails and bullet-proof vests. Unfortunately, at present the laser cutting system is too expensive for small apparel manufacturing companies, which make up the bulk of apparel manufacturers in the U.S.

\section{Demand-Activated Manufacturing Architecture}

The two devils of the apparel retail market are undersupply and oversupply, both of which are dictated by consumer demand. Undersupply results in empty shelves and fewer sales, and oversupply in price markdowns, wasted resources, and lost profits. In either case, the retailer's bottom line is adversely affected. With an eye to improving the entire U.S. textile marketplace, AMTEX envisions a secure, Internetbased information system to link all sectors of the textile supply chain. The key to this project is securely and selectively communicating demand information from retail

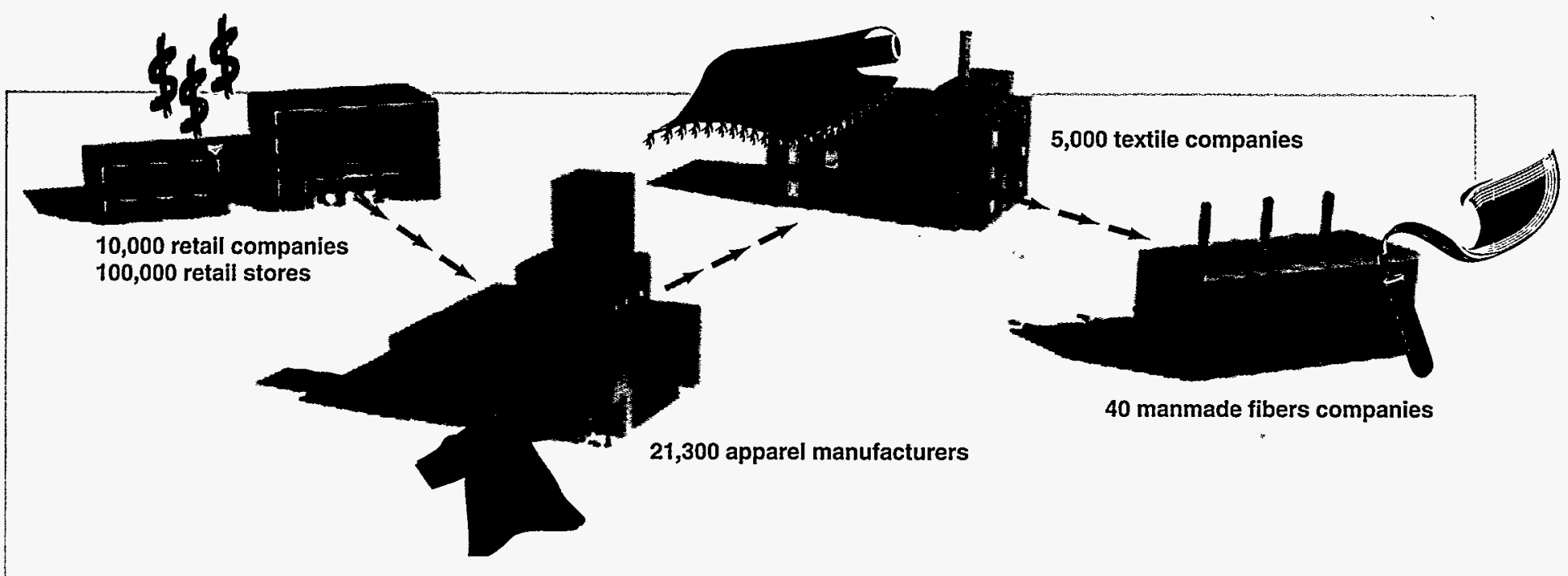

The amount of secure "demand" data to be transmitted over the Livermore-designed TEXTNET data transfer system will be enormous. Ten thousand retail companies with 100,000 stores, each with 25,000 to 1.2 million stockkeeping units, generate 20 billion apparel and household textile purchases annually worth about $\$ 200$ billion. That translates into electronic communication between apparel and textile manufacturers about the demand for 100 million industry stockkeeping units per year. 
companies back to apparel makers, textile manufacturers, and fiber producers. From analysis of point-of-sale data and sophisticated simulations of the entire industry, decision makers will be able to bring the right products to market at the right time at a competitive cost. The underlying assumption is that the entire textile pipeline has to operate more efficiently if there are to be significant gains for each of the four sectors. The figure on p. 21 gives an indication of the size of the industry and the volume of data the industry generates.

Several pairs of industry partners have been electronically transferring purchase orders and advance ship notices for several years over proprietary networks. These are typically "push" transfers in which, for example, a retailer provides sales information about a particular brand of pants to its manufacturer. The provider of the information initiates the transfer to the client and determines what data will be transferred and when.

Livermore is working with Idaho National Engineering Laboratory to develop TEXNET, which incorporates a demand-activated or "pull" transfer of data initiated by the client. For example, apparel

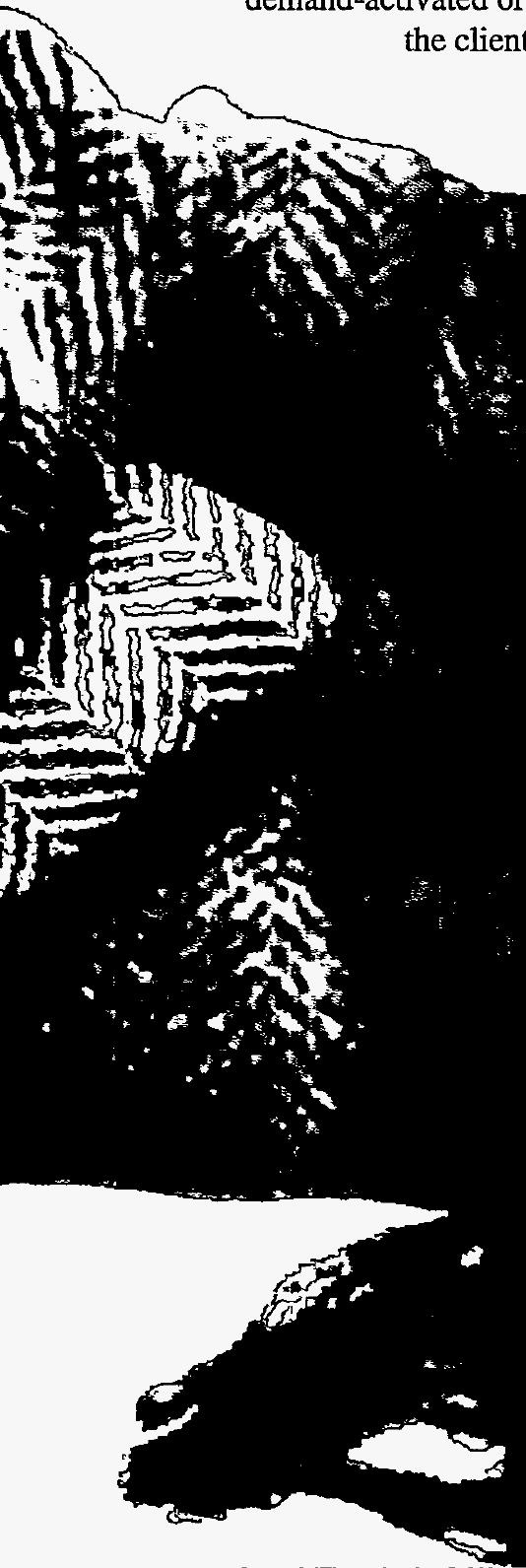
manufacturers will have "trading partner agreements" with a multitude of retailers and will regularly request sales and other information from them. Perhaps weekly, Brand A pants manufacturer will request sales information about Brand A pants, and Brand B pants manufacturer will do the same about theirs. Users will be assured that the information is provided not just securely but selectively as well-Brand A manufacturer must not receive information about sales of Brand $B$ pants. Such a system is currently impossible because there is no method for authenticating the identity of a client, i.e., for a retailer to electronically assure that the requester of information about Brand A pants is really Brand A manufacturer and not someone else.

Livermore is developing software for client authentication, which will make possible secure, selective transfer of data among multiple users. With the advanced encryption codes incorporated in this software, a data provider will be able to electronically assess a client's identity and validate its trading partner agreement before releasing client-specific information. The major challenge in designing the system has been the development of tools for implementing necessary security mechanisms.

Livermore is designing the whole TEXNET data transfer system, of which client authentication and management of trading partner agreements are parts. Because a client is receiving only a portion of the total data available, the bandwidth required for data transfer can be narrower than if all the data were to be transferred. Storage and processing requirements for the transfer system are also relatively small because only selected pieces of data are transferring at a time.

TEXNET is designed for the real-time exchange of virtually any type of information and may be customized by its users. Using the Internet, information can securely flow in any direction in the textile pipeline.

\section{Computer-Aided Fabric Evaluation}

Several years ago, Livermore developed a sensor that can track the path of a bullet as it flies through the air. This sniper detector can read the bullet's 
unique signals two hundred times a second from any direction and then track the bullet's path back to its source.

This same real-time, image-processing technology is being used for computer-aided fabric evaluation. Instead of looking at a bullet flying through the air, a camera and computer look for flaws in patterns being printed on fabric or in knitted fabrics. The system can not only detect defects in printing or knitting but can also immediately classify the defect and signal the machine operator that a problem exists and how to correct it.

Quick detection and correction of flaws will bring huge savings to textile manufacturers. For example, high-speed, fabric-printing machinery can handle both narrow and wide fabrics and may print hundreds of yards of material in just a few minutes. Lightly glued to a mat to provide an unmoving, stable surface, the greige fabric (pronounced "gray" and meaning undyed, unfinished fabric) passes under a series of roller screens, each of which prints a different color onto the fabric. A screen could slip slightly out of alignment causing a "misfit" where the dye is shifted on the fabric, a screen could become clogged with dye creating an unprinted area, or lint or thread could adhere to a print screen, also resulting in an unprinted area.

The proprietary system developed at Livermore mounts a high-speed, line-scan camera, or series of cameras depending on the fabric's width, over the fabric immediately after the last screen. (See photos on p. 20.) As the first yards of printed fabric roll beneath the cameras, the computer to which the camera is attached digitizes and dynamically learns the printed pattern by creating a model of the repeated pattern. The computer, powerful enough to handle the huge amounts of data that the process generates, can then inspect the printing process on line.

As it detects and diagnoses flaws, the computer accumulates a history of defects, which the computer draws upon in its reporting to the machine operator. For example, a one-time flaw might not initiate an alarm, but a repetition of small flaws or a large flaw would. Based on the array of defects that are known to occur, the computer's program determines what the problem is and what the operator's response should be. Depending on the particular setup, the operator is notified of the problem by bells, lights, or a printout on a computer monitor.

As the manufacturing facility's central computer accumulates data from the dedicated computers at the various fabric printers, quality control should improve considerably. Managers will have a record of problems with specific printing machines and with particular operators.

Livermore's system to detect flaws in knitted fabrics is very similar to that for detecting printing flaws. The flaws that crop up in the knitting process are different from those that appear in printing, but they can be dealt with by the computer in the same way.

By the time Livermore's work on computer-aided fabric evaluation is complete, pilot facilities will have been installed at the mills of several fabric manufacturers.

Key Words: AMTEX, computer-aided fabric evaluation, demandactivated manufacturing architecture, technology transfer, textiles, TEXTNET.

For further information about Demand-Activated
Manufacturing Architecture contact
Lansing (Chip) Hatfield (510) 422-8567
(hatfield1@IInl.gov).
For further information about Computer-Aided
Fabric Evaluation contact
Jose E. Hernandez (510) 423-2160
(hernandez5@IInl.gov).




\section{Rock Mechanics:}

\section{Can the Tuff Take the Stress?}

1 IGH school teachers and college students, working sideI. by-side with Laboratory geophysicists and geochemists, have had the rare opportunity to contribute to the field of geomechanics and to the study of how rocks fracture.

Obscure findings for esoteric studies of interest only to geologists, mining engineers, and rock hounds? Hardly.

The results are critical to understanding the behavior of a proposed underground repository for high-level radioactive wastes. The Yucca Mountain Repository in Nevada could become a permanent storage site for as much as 70,000 metric tons of nuclear waste, nearly $90 \%$ of it spent fuel from commercial nuclear power plants. ${ }^{1}$ Given the rigid federal, health, and safety regulations such a repository must meet, it is essential to understand how the surrounding rock behaves over time when exposed to heat and radiation generated by the nuclear waste.

At Lawrence Livermore, geomechanics expert Stephen Blair is a principal investigator conducting fundamental studies of the rock that would form the Yucca Mountain repositoryTopopah Spring tuff. (Tuff is formed of compacted volcanic fragments welded together.) In his quest for answers, Blair has enlisted the skikills and talents of eight high school teachers and college students, most of them recruited through the Laboratory's various education programs.

$\therefore a$

Stephen Blair (left), John Kelly, and Patricia Berge (rear) at work

- on a study of the effects of high temperature and intense

compression on the tuff from the Yucca Mountain, Nevada, area where a potential nuclear waste repository may be located.
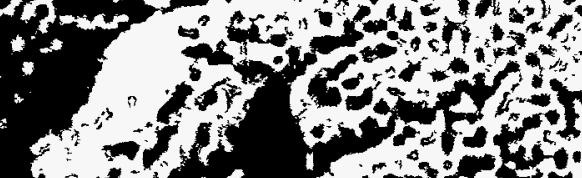

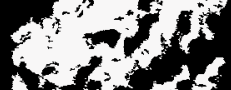
$f^{*}+\infty$ $+4$

r.
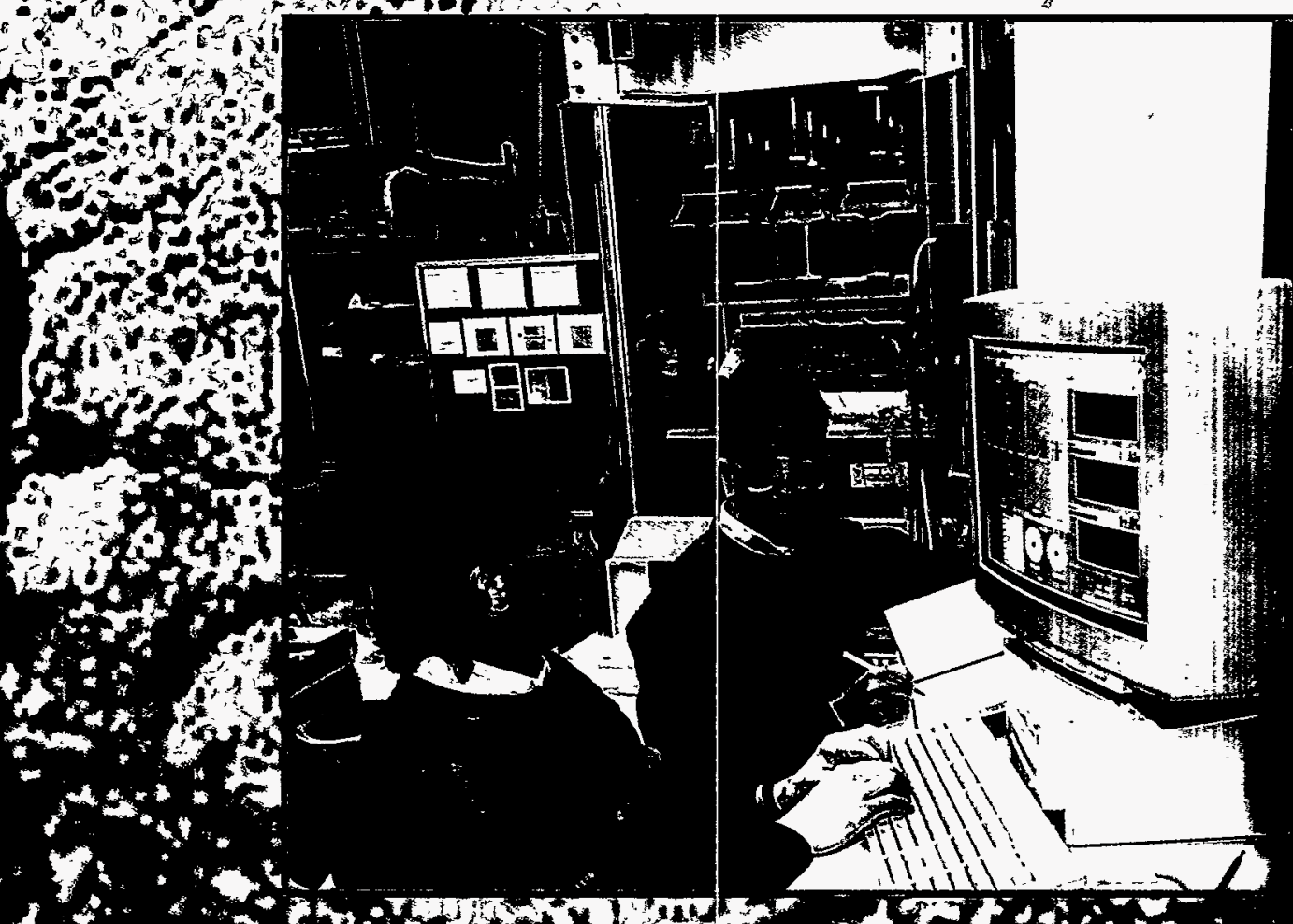
Questions that they are examining include: What happens when this rock is exposed to radioactivity over tens of thousands of years? As the temperatures increase and water in the pore spaces of the rock evaporates, how does that water move and what happens to the fractures and the rock itself? Blair and others have been conducting tests to better understand the structure of tuff and to develop and finetune computer models that will be used to determine the performance of the entire repository for hundreds of centuries. "We began with small rock samples, about the size and shape of a roll of quarters, looking at what happens at the pore level, basically the size of a grain of sand," said Blair. Three studies involving students and teachers focused on the behavior and structure of rock at this level. A fourth study examines how blocks of tuff a half-meter on a side behave under increasing temperatures and pressures.

\section{Grains and Pores}

The properties and behavior of the tuff depend on its grainscale structure and characteristics. Chris Pena, a graduate student in environmental engineering at San Jose State University, and Brian Johnson, a high school teacher now at Susanville, California, helped analyze the tuff microstructure. They used an image processing method-developed by LLNL's Blair, James Berryman and Patricia Berge-in which the microstructure of rocks is measured statistically. Under Blair's guidance, Pena used image-processing software to examine images of crosssections taken from tuff core samples from Yucca Mountain and to determine the rock's porosity, isotropy (directional dependence of material properties), and general structure. Among her findings, which she presented at the American Geophysical Union meeting in December 1995, was that the tuff material was dominated by small pores with crosssectioned areas of less than 10 square micrometers. ${ }^{2}$

Knowing the rock structure in such detail is important, Blair noted, because it is on this microlevel that cracks and fractures begin.

\section{Cracks and Fractures}

The grains of material that make up a piece of rock come in different sizes, shapes, minerals, strengths, and distributions.
Even the most uniform rock is diverse at the grain scale, and this diversity affects the processes of rock fracturing under stress. Under heat or pressure, tiny cracks form and merge to form larger fractures. These fracture processes are not well understood and are the subject of an ongoing study.

"One of the things that might happen at elevated temperatures and stresses in an underground nuclear repository is that cracks may form in the rock and the rock's properties might change," Blair explained.

Using a two-dimensional statistical computer model developed by Blair in 1994, Diablo Valley College student Austin Woffington and San Lorenzo high school teacher John Kelly simulated what happens when rock is compressed. In the model, the rock is represented by a lattice of grain centers that can be either "strong" (breaking only under high compression) or "weak" (breaking easily under moderate compression).

This model is being used to estimate the amount of cracking that will occur over time and at the high temperatures expected in the proposed repository. The results will aid in predicting the long-term integrity of the repository tunnels.

\section{Radiation and Rock Strength}

The tuff forming the repository must endure centuries of exposure to radioactive waste. What effect, if any, might this have on the rock? Will the rock weaken? Will it fracture more easily?

"We want to be sure radionuclides will stay in the repository," said Blair. "We need to better understand the effect radiation has on tuff and whether exposure to radiation will alter the mechanical strength or other geomechanical properties of the rock near the waste. Until now, there have been no data describing the effect of radiation on tuff from the potential repository."

A controlled study was performed to examine the effects of radiation on the strength of tuff. For this project, Blair enlisted the help of several high school teachers, including Kelly.

"We applied up to 160 megapascals-about 10 tons of forceto rocks the size of a roll of quarters, some of which had been subjected to gamma radiation," Kelly said. "The results were impressive to watch. Samples with pre-existing cracks just crumbled. With others, nothing happened until they failed catastrophically at high stresses." 
Preliminary results indicated that whereas radiation had little or no effect on initially unfractured samples, it did affect samples with pre-existing open fractures. These irradiated samples failed at stresses only half those applied to the non-irradiated samples. ${ }^{3}$

"One explanation is that radiation weakened the cementing material in the cracks," said Blair. "We need to do additional studies to say for certain. However, if this is a real phenomenon, it has significant implications. The radiation is expected to penetrate only a few centimeters into the rock. But this rock will also experience high temperatures, stresses, and humidity. If the fracture-filling materials are weakened, more pieces

\section{The Bennefits of Collaborration}

Blair is one of many-Lahorator principal investigatorstwho occásiogallywomploystudents, teachers, and faculty through the Laboratory,s Education'program. in time, for fort, and money and that hayengeneral tasks - student and $t^{2}$ teachers ban fill a niche The radiationt tests are gn example. Teaches and*

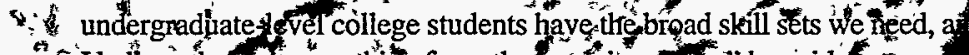
" : I believe they,get something from the experiene too," he said "

High schobl teacher John Kelly and collegestudents, Chris Pend tones Austin Woffington agree.

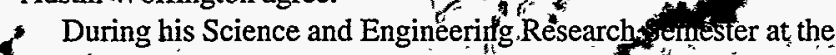
Laboratory, Woffington increased his knowyletge of geology, worked with a variety of software programs, and tearned to give effective technicàl presentations.

"The networklng with other scientists and students was extremely valuable to me," saidr.Woffingtìn. After getting to know scientists in the Environmental Programs Directorate, he developed an interest in groundwater modéling.

Chris Pena, now'a graduate stildent at San Jose State University in environmental engineering, was introducetuto the Laboratory through one of her SJ́SU uñ dergraduate professors.

With Blair âs a mentor, she honed her analytical and research skills and gained valuable experience writing technical papers and giving technical

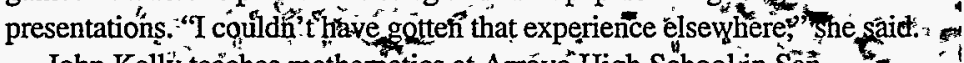
John Kelly teảches mathematics at Arróyo High School in Sân Lorenzo. His summers aţ the Laboratory as part of the Summer Research Internship Program for teachers helped him become onef two fephnical "mentor teachers" for the San Lorenzo School District."As a mentor" teacher, I conduct technical workshops for other feathers and work on the district's Educational Technology, Commifftee," he said

Blair also sees a benefit in direct outreach to the public. "This is a way to get grassroots support for science and rêsearch, "Whe explained. "Stúdents * * and teachers talk about their Laboratory experiences and pass on what they" have leamed. Those who come to us are the ones who go the extra mile, who are ambitious and curious. They may be futureleaders, and we have a golden opportunity to.introduce them to the value of researchand broaden their experience. Who knows? Some may work in
someday and be future collaborators as well." might break off over time. In addition, changes in fracture properties $\rightarrow$ such as fracture shear strength, compressibility, and permeability-could also occur. The rock mass may be affected in unanticipated ways, including movement of rock blocks along fractures."

\section{Next Step Up}

Blair's next step is to take a block of tuff a half-meter on a side (basically the size of a large computer monitor), subject it to increasing pressures while varying the temperature, and measure the deformation.

One block has been tested so far. San Jose State student Owen Pine did the data reduction and analysis on the first block of the series. Those results indicated that almost all the deformation in the block occurred across fractures and voids. ${ }^{4}$ Additional tests were completed recently.

"The results have significant implications for the flow and transport properties of the rock," said Blair. "For instance, it appears that cracks, fractures, and other open spaces perpendicular to the maximum principal stress will close over time. That means the rock will become less permeable in this direction. In addition, the tests show that pre-existing hairline cracks parallel to this stress may open over time. That will increase the permeability of the rock in that direction."

In the next test, Blair and his colleagues will add water to examine how water flow through the blocks of rock varies with pressure, temperature, and time.

Key Words: geomechanics, nuclear waste repository, tuff, Yucca Mountain Project.

\section{References}

1. For more information on the Yucca Mountain Project and the Laboratory's role, see "The Safe Disposal of Nuclear Waste," Science \& Technology Review, UCRL-52000-96-3 (March 1996), pp. 6-16.

2. C. Pena, S. C. Blair, P. A. Berge, Image Analysis of Tuff from the Yucca Mountain Project (Abstract). 1995 Fall Meeting, American Geophysical Union, December 1995.

3. S. C. Blair, J. M. Kelly, O. Pine, R. Pletcher, P. A. Berge, Effect of Radiation on the Mechanical Properties of Topopah Spring Tuff, Lawrence Livermore National Laboratory, Livermore, CA, UCRL-ID-122899 (January 1996).

4. O. Pine, S. C. Blair, P. A. Berge, Mechanical Behavior of a $0.5 \mathrm{~m}$ Block of Topopah Spring Tuff under Uniaxial Compression. 1995 Fall Meeting, American Geophysical Union, December 1995.

For further information about the rock mechanics projects contact Stephen Blair (510) 422-6467 (blair5@IInl.gov).

For further information about the Laboratory's Education Program contact Eileen Vergino (510) 422-3907 (verginoes@IInl.gov).

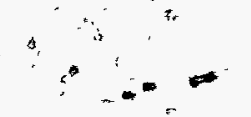


Richard H. Sawicki Terry W. Alger Raymond G. Finucane Jerome P. Hall

Segmented Lasing Tube for High Temperature Laser Assembly

U.S. Patent $5,497,392$

March 5, 1996
A ceramic lasing tube having a plurality of cylindrical segments of the same inner and outer diameters nonrigidly joined together in axial alignment; insulation of uniform thickness surrounding the lasing tube; a ceramic casing, preferably of quartz, surrounding the insulation; and a fluid-cooled, metal jacket surrounding the ceramic casing.

John M. Halpin

\section{Large Core Fiber Optic Cleaver}

U.S. Patent $5,501,385$

March 26, 1996
A device and method for cleaving optical fibers with core diameters greater than $\mathbf{4 0 0}$ micrometers to produce high-damage-threshold end surfaces. The device includes scribing means, a chuck assembly, and a fiber connector block. The fiber is scribed and then biased to apply cleaving tension.
Daniel M. Makowiecki Nano-engineered Explosives

U.S. Patent $5,505,799$

April 9, 1996
An explosive and fabrication method having a plurality of very thin, stacked, multilayer structures, each composed of reactive inorganic components separated by an organic component such as carbon. Upon detonation, the separator material reacts with the inorganic components to generate high temperatures and produce a working fluid or gas.
Organic Aerogel Microspheres and Fabrication Method Therefore

U.S. Patent $5,508,341$

April 16, 1996
The formation of organic aerogel microspheres ranging from about 1 micrometer to about 3 millimeters in diameter by inverse emulsion polymerization with agitation. The aerogel microspheres can be pyrolyzed to produce doped or undoped carbon aerogel microspheres. The size and structure of the microspheres are determined by the processing procedures and the chemical formulation.

\section{Stephen E. Sampayan Flat Panel Ferroelectric Electron \\ William J. Onvis \\ Emission Display System}

George J. Caporaso

Ted F. Wieskamp

U.S. Patent $5,508,590$
April 16, 1996

Kurt H. Weiner

\section{Method for Materials Deposition by} Ablation Transfer Processing

U.S. Patent 5,508,065

April 16, 1996
A device that can produce a bright, raster-scanned or non-rasterscanned image from a flat panel by relying on electrons emitted from a ferroelectric emitter impinging on a phosphor. This device, unlike many flat panel technologies, does not require ambient light or auxiliary illumination for viewing the image.

A process in which a thin layer of semiconducting, insulating, or metallic material is transferred by ablation from a source substrate (which is coated uniformly with a material of a desired thickness) to a target substrate by means of a pulsed, high-intensity, patternable beam of energy.

Clinton M. Logan

\section{Cooled Window for X-Rays or Charged Particles}

U.S. Patent $5,509,046$

April 16, 1996

Time-of-Flight Radio Location System

U.S. Patent $5,510,800$

April 23, 1996
A window that is capable of handling the thermal load from scattered $x$ rays, electrons, or ions. The window offers good structural integrity and a very high capacity for removal of heat with minimum attenuation of the beam. The window has microchannels inside it through which coolant is pumped to cool the window.

Thomas E. McEwan

A method and apparatus for detecting time-of-flight of electromagnetic pulses from a transmitter on an object to a receiver by sampling the pulses with controlled timing such that the time between transmission and sampling sweeps over a range of delays. An equivalent time sample signal is produced that can be processed to indicate object position.

Thomas E. McEwan

\section{Homodyne Impulse Radar Hidden Object Locator}

U.S. Patent $5,512,834$

April 30, 1996
An electromagnetic detector and method in which a homodyne oscillator modulates pulses from a pulse generator and transmits them to a hidden object. Reflected pulses are detected by a receiver that includes a sample and hold circuit that is gated by the pulse generator to produce an averaged detected signal. The receiver includes an AC coupled amplifier and a rectifier connected to the homodyne oscillator to demodulate the detected signals. 


\section{Celebration pays tribute to patent recipients}

Lawrence Livermore this spring honored 127 employees for their work on 881995 patent-winning technologies that deal with everything from chromosome staining to groundwater purification.

During the spring ceremony, Alan Bennett, director of the Lab's Industrial Partnerships and Commercialization office, spoke of the importance of patents for the Laboratory and the nation. "Patents help Livermore carry out R\&D partnerships with industry," he said. "They also help us see that technology developed in the course of our mission-related work has the maximum positive impact on the U.S. economy."

In addition, patents generate revenue for LLNL. Last year, Bennett reported that the Laboratory received a total of $\$ 1.1$ million in royalty income from licenses granted to private industry for use of patented Lab technologies. Contact: Alan Bennett (510) 423-3330 (bennett18@IInl.gov).

\section{Chiao returns to tell of spacewalking adventures}

Astronaut Leroy Chiao, who made his first journey into space in 1994 and ventured from NASA's Endeavor Space Shuttle in January 1996 for a pair of spacewalks, says he hopes to stay at NASA for at least one more mission, perhaps to get involved in building the space station.

Chiao made the comment this spring as he related his spacewalking experiences to an audience at Lawrence Livermore, where he has strong ties. Selected by NASA as an astronaut in January 1990, Chiao has been on a leave of absence from the Laboratory since July of that year. Before joining NASA, he worked in the Chemistry and Materials Science Department on processing research for fabrication of filament-wound and thick-section aerospace composites. Contact: Lawrence Livermore Media Relations Office (510) 423-3118.
Fisher named to lead Lab's DoD Programs Office

Roger E. Fisher has been selected to serve as director of Lawrence Livermore's Department of Defense (DoD) Programs Office. His appointment was announced in May by Laboratory Director Bruce Tarter.

In the position, Fisher is responsible for assisting Livermore directorates in development of new R\&D initiatives that match Laboratory capabilities with Defense Department technical requirements. Fisher also facilitates and coordinates the Laboratory's interactions with $\mathrm{DoD}$, and oversees the quality and effectiveness of the Laboratory's support efforts for DoD.

Fisher brings to Lawrence Livermore many years of experience in national security work, including holding a number of senior-level positions in the Department of Defense. He served most recently in the Department of Energy as deputy assistant secretary for Research and Development in Defense Programs, reporting to DOE Assistant Secretary Vic Reis. Contact: Lawrence Livermore Media Relations Office (510) 423-3118.

\section{What's that fungus among us?}

Long recognized for its depth and breadth of expertise, the Laboratory recently was contacted for its know-how in an arcane field: molds. The national Centers for Disease Control came to the Laboratory for technical assistance on the toxicity of household molds. CDC is considering possible contamination of some Fresno homes by a mold that can produce toxic chemicals. The chemicals-called mycotoxins-can be harmful to the immune and nervous systems. Lab industrial hygienist Rick Kelly specializes in the identification and control of exposure to toxic chemical and physical agents. He has a particular interest in mycotoxins formed by molds that can be found in offices and industrial sites and that eventually are released to the air. Kelly is consulting with the CDC in their investigation. Contact: David Schwoegler (510) 422-6900 (newsguy@IInl.gov). 


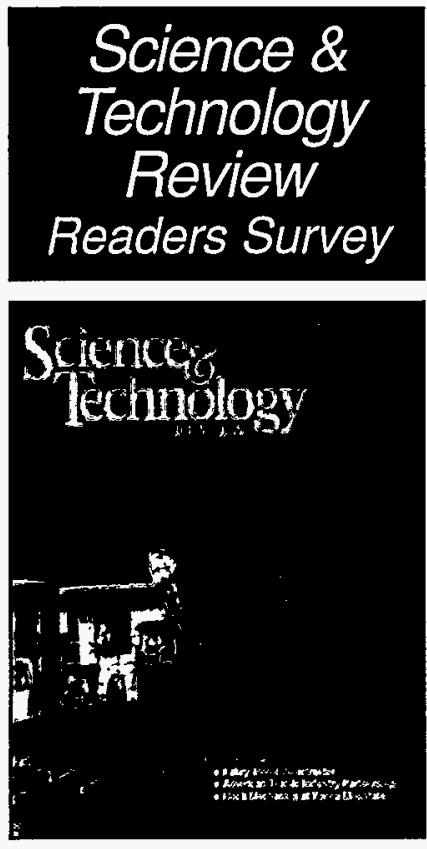

\section{Let Us Know What You Think}

Please answer this survey to help us improve our communication with you. It only takes a few moments.

\section{How to send us this survey:}

- FAX this sheet to $(510) 422-8803$,

- Fold, staple, and mail (address on back), or

- E-mail. Our homepage (http://www.Ilnl.gov/str) has an electronic form. Check the boxes, enclose a short note if you wish, and send the preaddressed e-mail to us.

\section{Rate your interest}

How interesting did you find the following articles?

Frontiers of Research in very interesting interesting minimal none

Advanced Computations

The Multibeam Fabry-Perot Velocimeter: Efficient

Measurement of High Velocities $\square$

High-Tech Tools for the

American Textile Industry

Rock Mechanics for Waste

Repository at NTS

How would you rate the technical level of the content?

Frontiers of Research in acceptable too high too low didn't read

Advanced Computations

The Multibeam Fabry-Perot

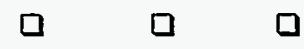

Velocimeter: Efficient

Measurement of High Velocities

High-Tech Tools for the

American Textile Industry

Rock Mechanics for Waste

Repository at NTS

How interesting do you find our new sections?

$\begin{array}{lcccc} & \text { very interesting } & \text { interesting } & \text { minimal } & \text { none } \\ \text { Laboratory News } & \square & \square & \square & \square \\ \text { Highlights } & \square & \square & \square & \square \\ \text { Patents } & \square & \square & \square & \square \\ \text { Commentary } & \square & \square & \square & \square\end{array}$

Comments

\section{Please check the box that most closely describes your} organization

\section{$\square \mathrm{DOE}$}

$\square$ LLNL employee

$\square$ Scientific or technical laboratory

Local, county", or state official or staff

$\square$ Staff/student at educational institution

$\square$ Other

\section{Electronic access}

Do you have access to the Internet?

$$
\square \text { yes } \square \text { no }
$$

If so, did you see our homepage? (http://www.llnl.gov/str)

$$
\square \text { yes - } \square \text { no }
$$

Did you try to access the references or pdf files?

$$
\square \text { yes } \square \text { no }
$$

\section{How to receive more information}

Additional information, generally written for an expert scientific audience, is available for the following articles. Please check the articles about which you would like more information.

\section{口 Frontiers of Research in Advanced Computations \\ $\square$ The Multibeam Fabry-Perot Velocimeter: Efficient Measurement of High Velocities \\ a High-Tech Tools for the American Textile Industry \\ $\square$ Rock Mechanics for Waste Repository at NTS}

\section{Subscription information \\ $\square$ Address correction $\quad$ New subscription \\ $\square$ Please drop me from your mailing list}

Name

Title

Organization

Address

City, State, Zip $\square$ Congressional leader/staff

$\square$ Industry

$\square$ Government agency

口 UC Regent 


\section{BUSINESS REPLY MAI}

\begin{tabular}{ll} 
First Class & Permit No. 16 Livermore, CA \\
\hline & Postage will be paid by LLNL
\end{tabular}

University of California

Lawrence Livermore National Laboratory

Attn: Science \& Technology Review

L-664

P. O. Box 808

Livermore, CA 94551-9989 